\title{
Segregação socioespacial e inserção no mercado de trabalho na Região Metropolitana de Campinas
}

\author{
José Marcos Pinto da Cunha* \\ Alberto Augusto Eichman Jakob ${ }^{* *}$
}

\begin{abstract}
Partindo da premissa de que o "espaço importa", o presente estudo procura contribuir para os esforços analíticos voltados a investigar o impacto da segregação, aqui entendida como a concentração no espaço de estratos socioeconômicos semelhantes, sobre a capacidade de respostas das pessoas ou famílias aos vários problemas e riscos observados nas grandes aglomerações urbanas. Mais especificamente, este artigo pretende investigar, para o caso de uma região metropolitana emergente no Brasil (Campinas, no Estado de São Paulo), se há evidências do efeito da segregação sobre distintas características da inserção dos indivíduos no mercado de trabalho. A partir dos dados do Censo Demográfico de 2000, analisa-se de que forma o desemprego, a formalidade do trabalho e a proteção social da população economicamente ativa estariam influenciados tanto pelas características sociodemográficas, incluindo status migratório e condição de mobilidade intraurbana (pendularidade), quanto por sua localização no espaço regional. Como variável espacial relativa à segregação, propõe-se uma medida baseada no Índice de Moran Local, que busca identificar áreas homogêneas em termos da composição socioeconômica de seus habitantes. Os resultados obtidos, embora não conclusivos, sugerem a importância da localização sobre a forma de inserção dos indivíduos no mercado de trabalho, o que corrobora algumas proposições teóricas levadas em conta nesse estudo.
\end{abstract}

Palavras-chave: Segregação residencial. Mercado de trabalho. Mobilidade espacial da população.

\section{Introdução}

Os impactos da segregação socioespacial sobre as condições gerais de vida da população e das famílias têm sido amplamente discutidos na literatura nacional e na internacional. Como mostra Flores (2006), os mecanismos que atuam para a efetivação desse efeito seriam identificados segundo distintas abordagens, cada uma delas com ênfase em aspectos diferentes, que vão desde questões relativas à existência de capital social, até as que enfatizam os diferenciais das localizações quanto a acesso aos serviços e demais oportunidades disponíveis em nível regional.

Partindo da premissa de que o "espaço importa” (FLORES, 2006; TORRES; FER-

\footnotetext{
* Professor do Instituto de Filosofia e Ciências Humanas - IFCH e pesquisador do Núcleo de Estudos de População Nepo da Universidade Estadual de Campinas - Unicamp.

** Pesquisador do Núcleo de Estudos de População - Nepo da Universidade Estadual de Campinas - Unicamp.
} 
REIRA; GOMES, 2005), pode-se investigar um conjunto de riscos ou comportamentos, na tentativa de avaliar o real impacto da segregação socioespacial, aqui entendida como a concentração no espaço de estratos socioeconômicos semelhantes, sobre a capacidade de resposta das pessoas ou famílias a estes problemas, ou, de maneira mais geral, seus efeitos sobre a inclusão social. Esse tipo de análise tem sido feito, por exemplo, em relação ao rendimento escolar das crianças (CUNHA; JIMÉNEZ, 2006; CUNHA et.al. 2007; TORRES; FERREIRA; GOMES, 2005; FLORES, 2006), às condições de vida dos jovens (GALSTER; MIKELSONS, 1995) ou mesmo à criminalidade (SAMPSON; RAUDENBUSH; EARLS, 1997).

No caso do Brasil, tais estudos vêm recebendo atenção cada vez maior de demógrafos, sociólogos e urbanistas, que, em geral, têm como foco as regiões metropolitanas, onde não apenas as dinâmicas, mas também os problemas sociais tornamse mais complexos e exacerbados, tendo em vista a concentração demográfica e a integração espacial existentes entre distintas unidades administrativas. O presente estudo pretende somar-se a essa linha de análise.

São três os objetivos desse artigo: apresentar sucintamente a situação regional em termos de sua dinâmica demográfica e processo de segregação socioespacial, em particular incluindo dados sobre a distribuição espacial da população segundo categorias socioocupacionais; avaliar, a partir de uma análise exploratória, os diferenciais observados em termos de inserção no mercado de trabalho, segundo características sociodemográficas, incluindo a mobilidade espacial e, particularmente, suas localizações no espaço metropolitano; e desenvolver um modelo multivariado, procurando isolar o efeito da localização sobre a inserção laboral, que, nesse estudo, será avaliada a partir dos indicadores de desemprego, condição de formalidade do trabalho e proteção social.

Tendo em vista que, no Brasil, a despeito de alguns avanços em termos de pesquisas domiciliares, ${ }^{1}$ o Censo Demográfico tem sido a fonte mais rica para estudos desse tipo, sobretudo devido à sua capacidade de desagregação espacial, esse estudo terá sua análise baseada nessa fonte para o ano de 2000. Além da possibilidade de conhecer as características da população em uma escala intramunicipal (setores censitários e áreas de ponderação2), estes dados permitirão aplicar técnicas espaciais para efeito da construção de indicadores de segregação.

\section{Mercado de trabalho, segregação e mobilidade espacial: algumas questões contextuais e teóricas}

\section{A situação do mercado de trabalho no Brasil: um breve apanhado}

O estudo de Dedecca e Baltar (1999) ajuda a entender, entre outras questões, as condições que levaram o Brasil a modificar significativamente o perfil e as condições do seu mercado de trabalho, em particular a partir dos anos 1980. Tendo em vista a intensa migração rural-urbana observada nos países latino-americanos e diante da limitada capacidade de absorção dos setores modernos presentes nos grandes centros receptores de população migrante, uma parte da força de trabalho disponível foi obrigada a buscar inserção nas atividades que exigiam menor qualificação, como comércio ambulante, serviços de reparação e conservação domiciliar e serviço doméstico.

Para estes autores, o desenvolvimento socioeconômico latino-americano foi inca-

\footnotetext{
1 Entre elas destacam-se os surveys realizados pelo Centro de Estudos da Metrópole, em 2006, e o recentemente terminado pelo "Projeto Vulnerabilidade", do qual esse texto é parte integrante, que coletou informações de mais de 1.800 domicílios na região em questão.

2 Os setores censitários são as menores unidades geográficas de referência para a coleta de informações censitárias. Já as áreas de ponderação são unidades geográficas formadas por um agrupamento mutuamente exclusivo de setores censitários. Enquanto para os setores censitários os dados disponíveis correspondem ao boletim de coleta relativo ao universo da população, portanto, com um número restrito de informações, para as áreas de ponderação, encontram-se disponíveis os dados relativos ao boletim de coleta da amostra, que contam com um volume muito maior de características relativas aos domicílios e às pessoas.
} 
paz de possibilitar a consolidação de um mercado de trabalho homogêneo, em que predominassem as situações de ocupação plena e protegida, com o desemprego restringindo-se ao friccional e a ocupação não-organizada ${ }^{3}$ constituindo mero resíduo. No que diz respeito aos anos 1990 e começo dos 2000 , os autores afirmam ainda que os países da região depararam-se com a ampliação da heterogeneidade socioeconômica explicada por alguns fatores, como a crise prolongada e, em especial, os efeitos destrutivos dos programas recentes de liberalização econômica.

Esta situação também pode ser entendida a partir de discussões empreendidas por outros autores, como Harvey (2005), Castells (1999) e Sassen (1991), que reconhecem a emergência, não apenas na América Latina (onde talvez este processo se revele de forma mais aguda), mas também em termos mundiais, de uma nova situação com a crise e a reestruturação produtiva.

Para Sassen (1991), a globalização da economia estaria provocando profundas reestruturações nas grandes cidades, que passariam por um intenso processo de reestruturação, particularmente em termos do mercado de trabalho. Esta nova estruturação, embora variável entre cidades, teria um impacto comum em todas elas: a emergência de uma nova estrutura social, caracterizada não só pela concentração de renda e expansão de segmentos ricos e segmentos pobres, mas também por uma contração da classe média.

Embora essa posição defendida por Sassen não seja necessariamente compartilhada por outros estudiosos, que, ao contrário, assumem como hipótese de trabalho o crescimento da heterogeneidade socioespacial na cidade (PRETECEILLE, 2000), o fato é que as regiões metropolitanas brasileiras parecem ainda reproduzir, em muitos sentidos, ainda que com certas nuances e novidades, o processo de periferização e marginalização tão visível nos anos 1960 e, particularmente, nos 1970.

Dedecca e Baltar (1999) destacam ainda outras mudanças no sistema produtivo: os programas de racionalização provocariam a desverticalização das grandes plantas industriais, acarretando a externalização de parte de suas atividades e tornando-as importantes subcontratantes não só de força de trabalho, mas também de produção e serviços. Esse novo contexto induziria a uma reavaliação do papel do setor nãoorganizado na dinâmica do capitalismo. Este passaria a fazer parte da lógica de produção/ atividade do que Dedecca e Baltar chamam de "setor moderno". Neste processo, as atividades informais não somente receberiam os trabalhadores expulsos pelas atividades modernas em seu movimento de racionalização produtiva, como também seriam incorporadas ao seu ciclo produtivo.

Assim, a diminuição do emprego formal teria feito, por um lado, com que essas situações de informalidade se tornassem definitivas e, por outro, que os assalariados expulsos pelo setor organizado, na falta de um sistema de seguro-desemprego de longa duração, migrassem, forçosamente ou não, para o setor informal, acarretando importantes consequências sobre as condições gerais de reprodução social.

Em termos gerais, o Brasil chegou a 2000, momento considerado nesse estudo, com um desemprego da ordem de $15 \%$, sendo que, na RM de Campinas, esse indicador foi um pouco maior, cerca de $16 \%$. No entanto, como se sabe, essas cifras, já assustadoras, ainda escondiam uma situação ainda mais preocupante, tendo em vista a incidência das situações de empregos precários ou subemprego. Alguns dos dados aqui analisados corroboram estas tendências.

Como será visto mais adiante, existe um conjunto de atributos que podem reduzir ou incrementar essa situação de precariedade em termos da inserção labo-

\footnotetext{
${ }^{3}$ Na reformulação socioeconômica desencadeada a partir da década de 1970, o setor informal passou a ser denominado de segmento não-organizado, em contraste com a organização do setor moderno, de acordo com Dedecca e Baltar (1999). A diferenciação é basicamente ditada pela lógica do lucro e da acumulação de capital do setor organizado, que, ao comandar a dinâmica do conjunto da economia, regula também os espaços ocupados pelas atividades não-organizadas de maneira capitalista.
} 
ral, sendo uma delas, por hipótese, a área onde vive o indivíduo.

\section{Mercado de trabalho, segregação e mobilidade espacial da população}

Como já mencionado na introdução, existem linhas de investigação que procuram mostrar como a segregação socioespacial afeta determinadas dimensões das vidas dos indivíduos e famílias. Entre estes enfoques, destacam-se dois: aquele que, genericamente falando, está preocupado em captar os chamados "efeito de bairro" (JENCKS; MAYER, 1990); e um segundo baseado na ideia de que existiria uma "geografia de oportunidades" (GALSTER; KILLEN, 1995).

Na primeira abordagem são destacados diferentes mecanismos pelos quais a segregação incide sobre certos comportamentos ou fenômenos. Estudos a partir dessa perspectiva estariam preocupados, por exemplo, em examinar a força (ou debilidade) dos marcos normativos existentes nas comunidades (KAZTMAN; FILGUEIRAS, 2006), a forma como são difundidos os comportamentos e como se dá a socialização coletiva por meio de transmissão de "modelos de rol” (WILSON, 1987, KAZTMAN, 1999), ou o nível de controle social existente no bairro (SAMPSON; RAIDENBUSH; EARLS, 1997).

No segundo caso, ou seja, no enfoque atinente à geografia das oportunidades, $\mathrm{O}$ efeito do lugar onde se vive sobre o comportamento dos indivíduos e famílias estaria ligado a elementos objetivos existentes (ou não) nessas áreas, como acesso e qualidade dos serviços, em particular os públicos (saúde, educação, segurança, etc.), infraestrutura, característica do mercado de trabalho, etc. Porém, variações espaciais subjetivas, basicamente representadas pelas redes sociais existentes, também poderiam representar impactos significativos (GALSTER; KILLEN, 1995).

Na verdade, como se percebe, estes dois enfoques possuem elementos de contatos muito claros, já que, em ambos os casos, ao menos uma questão surge como importante para explicar "comportamentos" diferenciados segundo o local de residência das pessoas: a influência das redes sociais existentes nos bairros ou nas comunidades locais.

A partir destas premissas básicas, poderse-ia propor a seguinte pergunta: é possível afirmar que, uma vez controladas certas características individuais, haveria evidências de que a segregação socioespacial tem efeito sobre a forma de inserção dos indivíduos no mercado de trabalho?

Nossa hipótese de trabalho é, portanto, que o acesso ao mercado de trabalho não dependeria apenas dos atributos sociodemográficos individuais, mas também de outros elementos que, segundo o exposto, estariam ligados ao local de moradia do indivíduo.

Quanto às características sociodemográficas utilizadas nesse estudo, não é necessário se aprofundar sobre os efeitos que o sexo, idade, educação, estado civil e cor/raça ${ }^{4}$ reconhecidamente possuem sobre as possibilidades de inserção laboral. Os diferenciais encontrados para 2000, segundo estas variáveis, com relação ao desemprego, por exemplo, foram bem significativos no Brasil e em suas várias regiões (DEDECCA, 2006).

No entanto, algumas considerações precisam ser feitas no caso das outras variáveis empregadas nessa análise, em particular o status migratório e a mobilidade intraurbana cotidiana (pendularidade).

No primeiro caso, ou seja, quanto à condição migratória do indivíduo, poderse-ia supor que o tempo de permanência no local de residência seria um importante indicativo do grau de sociabilidade e/ou captação de capital social, na medida em que os laços sociais e conhecimentos tenderiam a se incrementar com o passar do tempo, bem como poderia ter influência na quantidade e qualidade das informações sobre as oportunidades disponíveis, sejam

\footnotetext{
4 É importante esclarecer que, no Brasil, o quesito cor é obtido a partir da autodeclaração das pessoas, sendo, portanto, uma variável que identifica as características fenotípicas do indivíduo. No entanto, tem sido utilizado para captar as desigualdades sociais e raciais provocadas pelo legado do passado escravista.
} 
estas em termos do mercado de trabalho, ou mesmo em outras dimensões essenciais para a reprodução social, como assistência social, mercado habitacional, etc.

Embora, da mesma forma que Sampson, Raidenbush e Earls (1997), acreditemos que a composição dos bairros em termos do tempo de residência de seus habitantes influenciaria a produção de capital social, consideramos também que os indivíduos tenderiam a se beneficiar mais ou menos destas redes e marcos normativos construídos, à medida que estivessem por mais tempo inseridos nesses contextos. Dessa forma, no presente estudo, considerou-se que o fato de o indivíduo ser migrante recente teria impacto sobre sua inserção laboral, particularmente no caso de pessoas com mais baixa qualificação, que, via de regra, migram para a região sem um emprego garantido.

Nessa mesma linha de argumentação, seria esperado, também, que o migrante intrametropolitano, tendo em vista sua experiência prévia na região e, portanto, uma provável maior acumulação de capital social e informações sobre a área, tivesse melhor desempenho do que aquele cuja residência prévia fosse fora da região. Por esse motivo, a variável utilizada na análise considerará não apenas a condição de migração recente, mas também a residência prévia do migrante. ${ }^{5}$

Um estudo recente (SOBREIRA; CUNHA, 2007) mostrou que, de maneira geral, a pessoa que fazia o movimento pendular encontrava-se, em 2000, em melhores condições tanto em termos de rendimentos quanto com relação ao desemprego. Na verdade, este resultado não chega a surpreender, pois a realização desse tipo de deslocamento só faria sentido, via de regra, no caso de pessoas inseridas no mercado de trabalho e, mais do que isso, com rendimentos ou benefícios patronais que viabilizassem tais movimentos, uma vez que, ao se tratar de viagens entre municípios, sempre haveria um custo substancial envolvido.
Na maior parte dos casos, especialmente para a população de baixa qualificação, o distanciamento com relação ao local de trabalho deve-se à busca por alternativas habitacionais. Nesse contexto, a pendularidade colocar-se-ia como uma "estratégia", como entendido por Bourdieu (1998), cujo propósito seria manutenção, reprodução ou melhoria da posição de um agente dentro de um campo determinado.

É bem verdade que, para esta parcela da população, embora a solução habitacional pudesse significar reais melhorias em suas condições de vida - por exemplo, a casa própria significaria não mais ter que pagar aluguel, ter mais segurança com relação ao futuro, etc. -, isso não quer dizer necessariamente que, no caso brasileiro, estas pessoas teriam melhores condições de moradia. De fato, para a população de baixa renda, a obtenção da casa própria implica, via de regra, a necessidade de se afastar das áreas mais bem providas de infraestrutura e acessibilidade, além de ter que se sujeitar a piores condições de habitabilidade, tendo em vista o baixo padrão construtivo de suas residências.

Por esse motivo, considera-se importante analisar o desempenho no mercado de trabalho também a partir dessa perspectiva, visto que a possibilidade de se mover dentro da região metropolitana pode interferir não apenas na forma, mas também na estabilidade de inserção no mercado de trabalho.

\section{A RM de Campinas: dinâmica demográfica e segregação socioespacial ${ }^{6}$}

A dinâmica de formação e expansão da RM de Campinas, área composta por 19 municípios e com cerca de 2,5 milhões de habitantes, apresenta estreita semelhança com o que se verificou em outras metrópoles do país, ou seja, deu-se em função de taxas expressivas de crescimento populacional e pela periferização do crescimento físicoterritorial, muito embora neste caso também

\footnotetext{
5 Neste estudo, o migrante é definido como aquele que, em 1995, residia em município distinto daquele em que foi recenseado. Além disso, estes serão subdivididos entre intrametropolitanos (município, em 1995, pertencente à RM de Campinas) e externos (município, em 1995, fora da RM da Campinas).

${ }^{6}$ Esse capítulo representa uma breve síntese de um trabalho mais completo recentemente publicado (CUNHA et al. 2006).
} 
existam claros indícios de que processos diversos, como o crescimento de subúrbios ${ }^{7}$ e de municípios que não a sede, também tiveram impactos.

Assim, na região, assistiu-se, por um lado, a uma "extensão" da mancha urbana, configurada como um clássico processo de periferização, em que os limites políticoadministrativos, na maior parte das vezes, acabam sendo puras abstrações ou arbítrios, e, por outro, a um crescimento de núcleos urbanos de outros municípios que, em alguns casos, como Americana, cidade com grande importância na indústria têxtil nacional, acabam por formar suas próprias periferias.

A partir dos anos 1960 e principalmente depois dos 1970, Campinas recebeu grandes investimentos governamentais, tornando-se um dos maiores eixos de expansão industrial no interior do Estado, em grande parte devido à desconcentração verificada a partir da Região Metropolitana de São Paulo, o que elevou enormemente seu ritmo de crescimento populacional, assim como de toda a região (Tabela 1 ).

Durante a década de 1980, a população desconcentrou-se da cidade de Campinas, dirigindo-se aos municípios vizinhos, transformando alguns deles em municípiosdormitórios, muito embora, em vários casos, a expansão industrial ocorrida ao longo de uma importante rodovia (a Anhanguera) tenha modificado, ou ao menos tornado mais heterogêneas, estas funções metropolitanas.

Existem várias direções para as quais a população metropolitana se expande. ${ }^{7}$ Contudo, estas não são homogêneas no que diz respeito tanto ao ritmo de crescimento demográfico e características socioeconômicas, quanto às suas funções metropolitanas. Algumas direções têm sido mais privilegiadas no processo de espraiamento metropolitano, como é o caso do eixo oeste (Mapa 1). Os municípios aí localizados apresentaram crescimento demográfico muito acima da média regional, tais como Hortolândia e Sumaré. Este comportamento apenas reforça um dos principais condicionantes do processo de redistribuição espacial da população na RM de Campinas: a busca por localizações que aliem preços da terra mais baratos e fácil acessibilidade. No entanto, em suas porções nordeste e sudeste, a região também apresenta áreas de expansão que se caracterizam por maior concentração da população mais abastada.

TABELA 1

População residente e taxas de crescimento demográfico

Brasil, Estado de São Paulo e RM de Campinas - 1970-2000

\begin{tabular}{|c|c|c|c|c|c|c|c|}
\hline \multirow[t]{2}{*}{ Localidades } & \multicolumn{4}{|c|}{ População } & \multicolumn{3}{|c|}{$\begin{array}{c}\text { Taxas de crescimento } \\
\text { (\% a.a.) }\end{array}$} \\
\hline & 1970 & 1980 & 1991 & 2000 & $1970-1980$ & 1980-1991 & $1991-2000$ \\
\hline Brasil & 93.134 .846 & 119.011 .052 & 146.825 .475 & 169.872 .856 & 2,48 & 1,93 & 1,63 \\
\hline Estado de São Paulo & 17.770 .975 & 25.042 .074 & 31.588 .925 & 37.035 .456 & 3,49 & 2,13 & 1,78 \\
\hline RM de Campinas & 680.826 & 1.276 .801 & 1.866 .025 & 2.338 .148 & 6,49 & 3,51 & 2,54 \\
\hline
\end{tabular}

Fonte: IBGE. Disponível em: <http://www.sidra.ibge.gov.br>. Acesso em 17 jan. 2008.

\footnotetext{
7 Embora não exista oficialmente uma classificação por localização geográfica dos municípios metropolitanos, utilzouse aquela proposta em outro estudo (CUNHA et al., 2006), a saber: Centro: Campinas; Oeste: Monte Mor, Hortolândia, Sumaré, Nova Odessa, Americana e Santa Bárbara d'Oeste; Norte: Artur Nogueira, Cosmópolis, Engenheiro Coelho e Paulínia; Nordeste: Holambra, Jaguariúna, Pedreira e Santo Antonio de Posse; Sudeste: Itatiba, Valinhos e Vinhedo.
} 


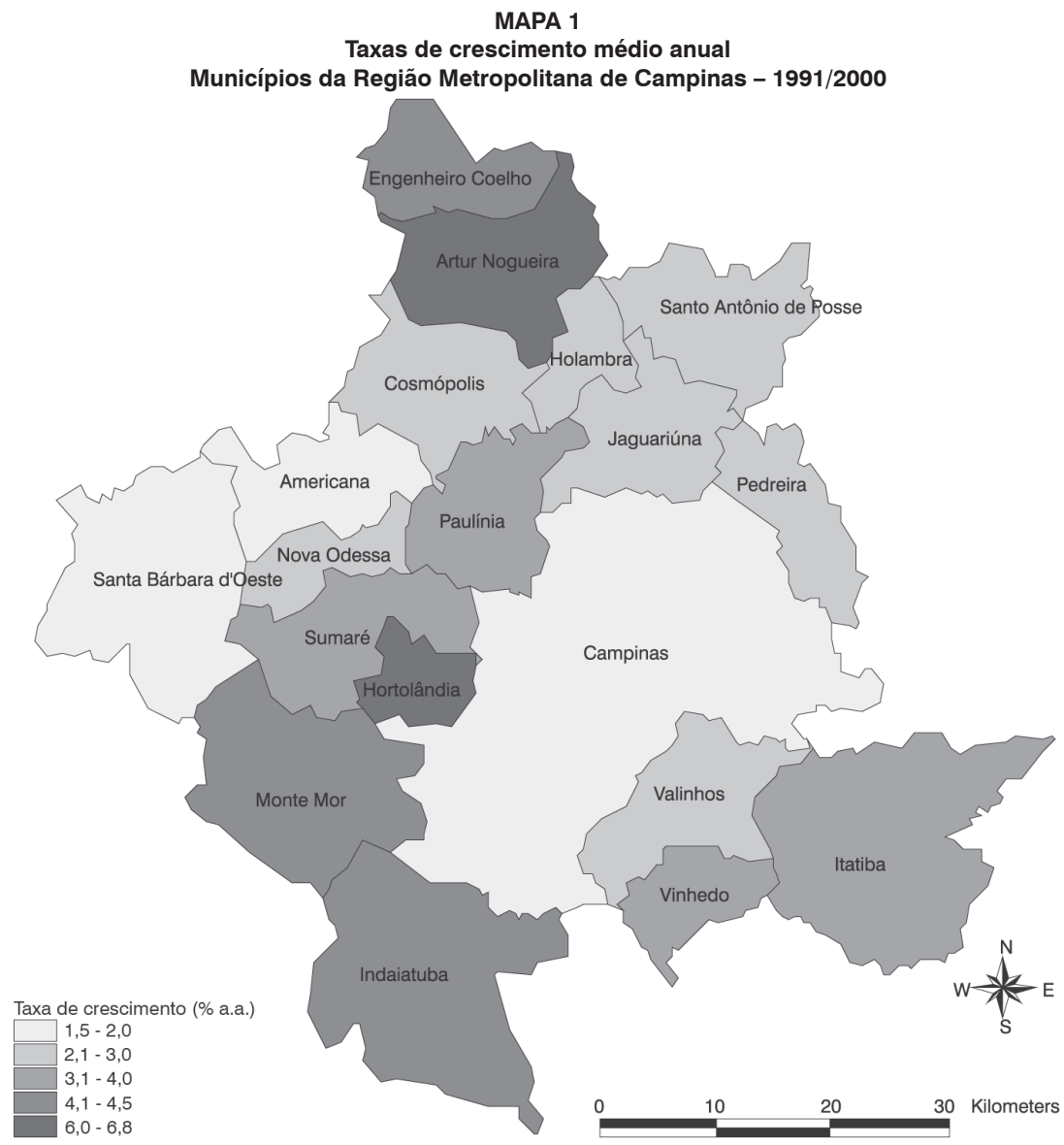

Fonte: IBGE. Censos Demográficos de 1991 e 2000.

Elementos da segregação socioespacial: a configuração das "cordilheiras sociais"

Estudos focados na segregação socioespacial mostraram que, embora mensurações clássicas de segregação, como o índice de dissimilaridade, evidenciassem uma redução do fenômeno ao longo dos anos 1990 na Região Metropolitana de Campinas, um olhar cuidadoso e tecnicamente mais elaborado não deixa dúvidas sobre a existência de uma importante clivagem socioespacial na área (CUNHA et al., 2006 e CUNHA; JIMENEZ, 2006).

A configuração das "cordilheiras da riqueza e da pobreza" poderia ser percebida tanto a partir do simples mapeamento da distribuição das famílias por renda no espaço metropolitano, quanto por meio de técnicas mais sofisticadas. Como se nota no Mapa 2, quando utilizado o Índice de Moran Local (detalhado mais adiante) para o nível de setores censitários e empregando o indicador "condição socioeconômica", 8 percebe-se a

\footnotetext{
8 Esse indicador sintético foi obtido a partir de uma análise fatorial que, além da dimensão socioeconômica, também utilizava outras características relativas à infraestrutura dos domicílios e composição familiar. O fator rotulado como "condição socioeconômica" respondeu, em 2000 , por cerca de $50 \%$ da variabilidade total e apresentava-se altamente correlacionado com a escolaridade e renda do chefe de domicílios, o que nos levou a considerá-lo representativo das condições materiais de vida e capital humano disponível (uma das dimensões da pobreza). Quanto mais alto for o valor desse indicador, maior será o grau de privação material e baixo capital humano. Para mais detalhes sobre esse procedimento, ver Cunha e Jiménez (2006).
} 
existência de fortes concentrações de população de riqueza e pobreza na Região Metropolitana de Campinas, mostrando, inclusive, que a segregação socioespacial regional não se restringe apenas à população mais pobre.

De fato, da mesma forma que boa parte da porção oeste da RM de Campinas apresenta grande concentração de famílias pobres (categoria Alto-Alto), na direção oposta, numa faixa que vai do nordeste ao sudeste da região, observa-se maior predominância de pessoas com melhores condições de vida.
Outra forma de avaliar o processo de segregação social na região seria a partir da análise da divisão regional do trabalho, que, entre outros efeitos, teria impacto sobre a composição da população, em termos dos estratos sociais, nos seus diferentes subespaços.

Com base em importante trabalho sobre estratificação social na América Latina elaborado por Portes (1985) e posteriormente atualizado por Portes e Hoffman (2003), analisou-se a situação da RM de Campinas a partir dessa perspectiva, utilizando-se os dados do Censo de 2000.9

MAPA 2

Resultados para o Índice de Moran Local para condição socioeconômica, segundo setores censitários RM de Campinas - 2000

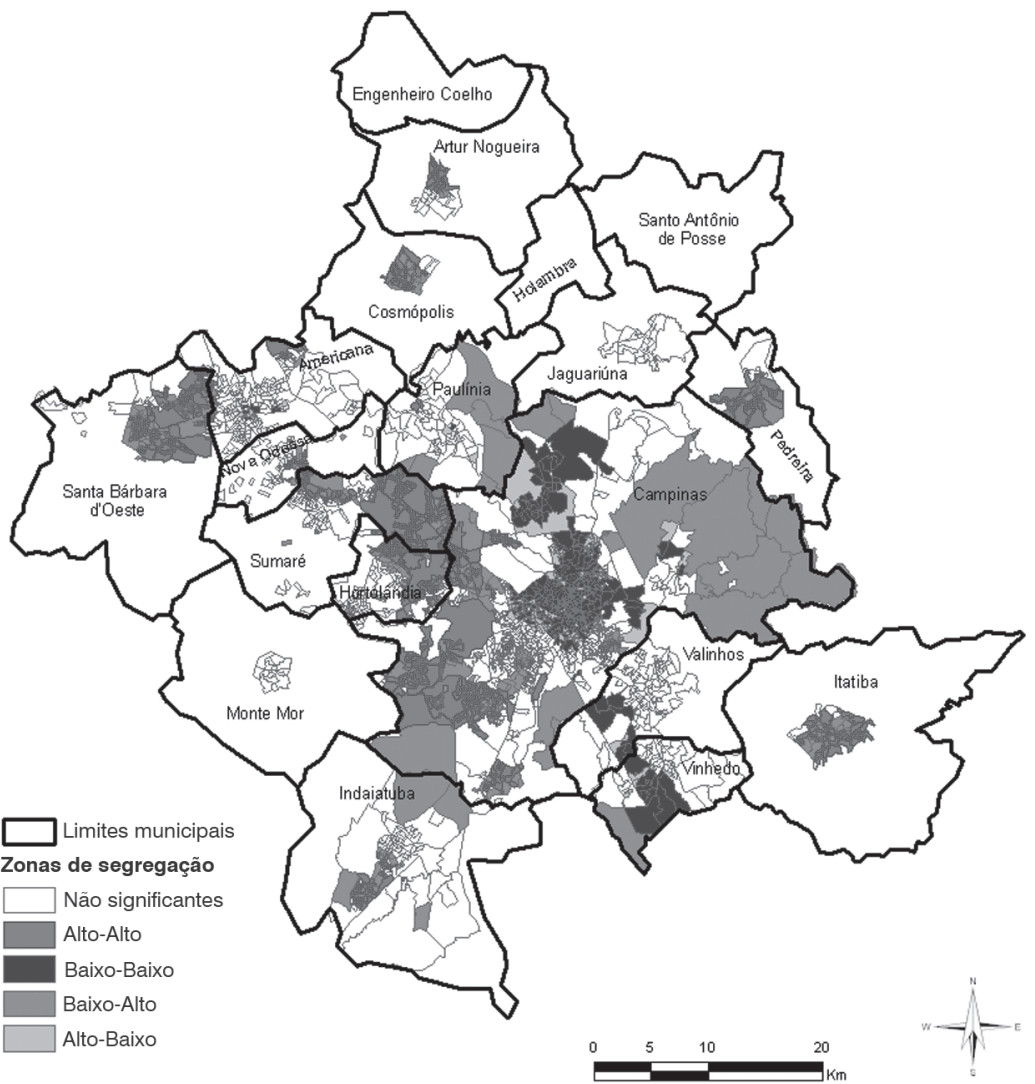

Fonte: Cunha e Jiménez (2006).

\footnotetext{
${ }^{9}$ Encontra-se em elaboração um estudo mais detalhado sobre a segregação socioespacial na RM de Campinas a partir destas categorias socioocupacionais. As categorias aqui analisadas, fruto de uma adaptação e simplificação da proposta de Portes para o caso brasileiro, poderiam ser resumidas nas seguintes: capitalistas, executivos e profissionais, microempresários, trabalhadores manuais, trabalhadores não-manuais e uma última categoria residual que, para o caso da RM de Campinas, representava, em 2000, apenas 0,5\% da população economicamente ativa maior de 14 anos de idade.
} 
A Tabela 2, que contém informações para alguns municípios metropolitanos selecionados, permite visualizar as claras diferenças entre a composição da população de municípios localizados na "cordiIheira da pobreza" e aquela residente na "cordilheira da riqueza". Além disso, da forma como estão apresentados, estes dados também possibilitam deduzir que o papel da migração, ao contrário de reduzir, parece ter contribuído para ampliar o processo de segregação.

De fato, observa-se que, enquanto para os municípios caracteristicamente dormitórios, como Hortolândia e Sumaré, a participação dos estratos "capitalistas" e "executivos e profissionais" é bem reduzida, o mesmo não se repete tanto em Campinas, como seria de se esperar, tendo em vista que é a sede regional, como em Valinhos e Vinhedo, que, como se sabe, têm sofrido um processo de elitização de sua população a partir dos anos 1990, quando começou a se generalizar, nesses municípios, a figura dos chamados "condomínios fechados" para a população de alta renda. Situação inversa ocorre quando a categoria "trabaIhadores manuais" é considerada. Ou seja, a proporção deste estrato social é muito mais elevada nas primeiras duas cidades mencionadas.

Mais interessante ainda é observar, por estes dados, que a migração estaria contribuindo para o aprofundamento da segregação socioespacial regional, pelo menos quando esta é tratada em nível municipal. De fato, enquanto nos municípios de maior concentração de pobreza (Hortolândia e

TABELA 2

Distribuição da População Economicamente Ativa com mais de 14 anos de idade, por categoria ocupacional, segundo condição de migração

Municípios selecionados da RM de Campinas - 2000

\begin{tabular}{|c|c|c|c|c|c|c|c|c|}
\hline \multirow{2}{*}{$\begin{array}{l}\text { Local de } \\
\text { residência }\end{array}$} & \multirow{2}{*}{$\begin{array}{l}\text { Condição de } \\
\text { migração }\end{array}$} & \multicolumn{6}{|c|}{ Categorias ocupacionais (\%) } & \multirow[b]{2}{*}{ Total } \\
\hline & & Capitalistas & $\begin{array}{l}\text { Executivos e } \\
\text { profissionais }\end{array}$ & $\begin{array}{l}\text { Microem- } \\
\text { presários }\end{array}$ & $\begin{array}{c}\text { Trabalhadores } \\
\text { manuais }\end{array}$ & $\begin{array}{c}\text { Trabalhadores } \\
\text { não-manuais }\end{array}$ & $\begin{array}{l}\text { Outros } \\
\text { (1) }\end{array}$ & \\
\hline \multirow{3}{*}{ Campinas } & Migrante & 0,9 & 11,5 & 18,0 & 47,3 & 21,6 & 0,7 & 40.060 \\
\hline & Não-migrante & 1,7 & 9,6 & 21,9 & 40,4 & 25,8 & 0,5 & 358.236 \\
\hline & Total & 1,6 & 9,8 & 21,5 & 41,1 & 25,4 & 0,5 & 398.296 \\
\hline \multirow{3}{*}{ Hortolândia } & Migrante & 0,3 & 2,9 & 18,9 & 61,0 & 15,9 & 1,1 & 12.807 \\
\hline & Não-migrante & 0,4 & 2,2 & 20,4 & 58,9 & 17,1 & 1,0 & 43.517 \\
\hline & Total & 0,3 & 2,4 & 20,1 & 59,4 & 16,8 & 1,0 & 56.324 \\
\hline \multirow{3}{*}{ Sumaré } & Migrante & 0,2 & 3,4 & 18,4 & 60,7 & 17,1 & 0,3 & 13.812 \\
\hline & Não-migrante & 0,3 & 2,6 & 19,3 & 60,9 & 16,6 & 0,4 & 61.743 \\
\hline & Total & 0,2 & 2,7 & 19,1 & 60,8 & 16,7 & 0,4 & 75.556 \\
\hline \multirow{3}{*}{ Valinhos } & Migrante & 2,3 & 11,6 & 22,1 & 47,2 & 16,8 & 0,1 & 5.913 \\
\hline & Não-migrante & 1,7 & 6,9 & 20,8 & 49,1 & 21,1 & 0,3 & 30.843 \\
\hline & Total & 1,8 & 7,7 & 21,0 & 48,8 & 20,4 & 0,3 & 36.756 \\
\hline \multirow{3}{*}{ Vinhedo } & Migrante & 2,9 & 12,3 & 20,9 & 44,1 & 18,9 & 1,0 & 3.701 \\
\hline & Não-migrante & 2,4 & 7,2 & 20,8 & 51,6 & 17,8 & 0,3 & 17.620 \\
\hline & Total & 2,5 & 8,0 & 20,8 & 50,3 & 18,0 & 0,4 & 21.321 \\
\hline \multirow{3}{*}{ Total RMC } & Migrante & 1,0 & 7,7 & 18,6 & 54,3 & 17,8 & 0,6 & 129.820 \\
\hline & $\begin{array}{l}\text { Não-mi- } \\
\text { grante }\end{array}$ & 1,4 & 6,6 & 21,2 & 49,2 & 21,0 & 0,6 & 821.946 \\
\hline & Total & 1,4 & 6,7 & 20,8 & 49,9 & 20,6 & 0,6 & 951.765 \\
\hline
\end{tabular}

Fonte: IBGE. Censo Demográfico de 2000. Tabulações especiais Nepo/Unicamp.

(1) Incluem os aprendizes ou estagiários sem remuneração, os não-remunerados em ajuda a membro do domicílio, os trabalhadores na produção para o próprio consumo e as ocupações mal especificadas. 
Sumaré) as diferenças entre as distribuições por estrato social de migrantes e nãomigrantes são praticamente desprezíveis, o mesmo não ocorre nos municípios da porção sudeste da região, onde os migrantes recentes encontram-se, em geral, em posições sociais mais privilegiadas do que os não-migrantes e muito mais concentrados nos estratos "capitalistas" e "executivos e profissionais" em detrimento, sobretudo, do estrato "trabalhador manual". Esse processo de "elitização" da população destas áreas, como já mencionado, é claramente compreensível em função do processo de transformação pelo qual passa essa zona da região metropolitana.

\section{Dados e métodos de análise}

\section{Fontes de dados e indicadores utilizados}

Os dados utilizados no presente estudo derivam-se do Censo Demográfico de 2000, que, além do nível municipal, permitem também desagregar a análise em uma escala intramunicipal. Considerando-se as hipóteses e proposições teóricas em que se baseiam este trabalho, os dados permitirão, por um lado, apreender as características sociodemográficas da população (sexo, raça/cor, idade, estado civil, condição migratória) e, por outro, construir um indicador de segregação socioespacial, a partir do qual será possível avaliar o comportamento das variáveis relativas à inserção no mercado de trabalho do indivíduo. Para tanto, foram criadas variáveis dicotômicas para a População Economicamente Ativa (PEA) maior de 14 anos, de acordo com os seguintes aspectos: desemprego; acesso ao trabalho formal; e acesso à seguridade social.

Será considerado desempregado o indivíduo maior de 14 anos, economicamente ativo que declarou estar sem trabalho no momento do Censo. No caso do trabalho formal, foram incluídas apenas as pessoas empregadas que possuíam carteira de trabalho assinada. Já a proteção social foi caracterizada pela existência de contribuição, por parte do indivíduo, empregado ou não, para algum sistema de seguridade social.

\section{Segregação socioespacial: conceito e} mensuração

O conceito de segregação socioespacial utilizado nesse texto tem como referência as considerações feitas tanto por Massey e Denton (1988) quanto por Sabatini (2004) e Sabatini e Sierralta 2006) com relação ao seu caráter multidimensional. Para os nossos propósitos, a medida de segregação a ser usada deveria refletir não apenas o grau de separação de um grupo social de outro, mas sobretudo o grau de agrupamento que estes estratos sociais apresentam no espaço metropolitano. Assim, buscaram-se medidas de segregação que tivessem a capacidade de desvendar o grau de homogeneidade (ou heterogeneidade) social existente na região, tendo como ponto de partida a semelhança (ou não) entre unidades espaciais vizinhas.

Assim, para analisar a dimensão definida como "clustering" por Massey e Denton (1988), que, segundo Sabatini e Sierralta (2006), seria a verdadeira e única medida de segregação residencial, optou-se por lançar mão de uma metodologia baseada em autocorrelação espacial, o Índice de Moran Local.

O Índice de Moran é um indicador de associação espacial que avalia a existência de conglomerados (clusters) na distribuição espacial de uma determinada variável, podendo ser calculado de forma localizada (Moran Local) para cada unidade espacial (no caso aqui os setores censitários do Censo 2000), assim como, a partir destas, obtido como medida geral (Moran Global), estatística que permite estabelecer o grau de aglomeração de unidades semelhantes ("clustering") existente na região analisada. Pelo Moran Local, é possível criar um mapa (como o apresentado nesse estudo), em que se podem detectar os setores censitários cercados por outros semelhantes ou não. Considerando a variável em estudo (a condição socioeconômica), os setores classificados como Alto-Alto (os chamados hot spots) seriam aqueles, em média, com piores condições rodeados por outros em condições semelhantes. Os Baixo-Baixo (cold spots) seriam aqueles setores com melhores condições socioeconômicos cer- 
cados por outros na mesma situação. Enfim, os Alto-Baixo envolveriam situações em que a zona circunvizinha do setor com más condições sociais seria formada por setores com melhores condições; Baixo-Alto seria a situação contrária. Da mesma forma, com essa técnica, é possível observar áreas com grande heterogeneidade (o que o modelo rotula de "não significante"). Esse indicador poder ser obtido a partir do software de domínio público GeoDA. Para mais detalhes sobre o método, ver Anselin (1995).

\section{A identificação das "zonas de segregação"}

Tendo em vista o conjunto de características dos indivíduos que se pretendia incorporar na análise, a criação de um indicador que pudesse categorizar os distintos subespaços de região encontrou algumas dificuldades com relação à unidade espacial de análise. Por um lado, o uso dos setores censitários, embora mais adequado para se apreender o fenômeno da segregação socioespacial, devido ao seu menor tamanho em termos territoriais, mostrava-se inviável, tendo em vista não apenas o número restrito de informações disponíveis a esse nível, mas também o fato de as características socioeconômicas serem captadas apenas para o chefe do domicílio.

Por outro lado, embora para o nível das áreas de ponderação (APs) todas as informações levantadas pelo questionário da amostra do Censo Demográfico estivessem disponíveis, seu tamanho, seja em termos de área, seja quanto à população, certamente não permitiria obter segurança sobre o grau de homogeneidade social dessa área.
A Tabela 3 permite que se tenha uma ideia de quão diferentes foram os resultados da aplicação do Índice de Moran Local para cada uma destas escalas para o indicador condição socioeconômica. Assim, por exemplo, enquanto mais de $32 \%$ dos setores censitários poderiam ser classificados na categoria Alto-Alto, apenas $18 \%$ poderiam ser mantidos nessa categoria se respeitada a classificação obtida pelo modelo a partir da análise ao nível de áreas de ponderação. Por outro lado, a maior incidência em nível de AP de zonas classificadas como BaixoBaixo levou a que o percentual de setores assim classificados passasse de $15 \%$ para cerca de $24 \%$. Ou seja, fica claro que a elevada agregação espacial das APs reduziria a percepção da real segregação existente.

Tendo em vista esse problema, foi proposta uma solução que mesclou os dois níveis espaciais, aproveitando-se as vantagens de cada um deles, ou seja, a desagregação espacial permitida pelos setores e a maior riqueza de informações acessíveis em nível de AP.

A ideia foi avaliar quanto da classificação obtida a partir das APs seria corroborada pela análise em nível de setores censitários. Em um primeiro momento, identificaram-se as $\mathrm{APs}^{10}$ que continham apenas setores com a mesma classificação. Assim, por exemplo, de um total de 111 APs da RM de Campinas, 48 puderam ser classificadas como "não significantes", tendo em vista que continham apenas setores nessa categoria. Ou seja, nas restantes 63 APs, a heterogeneidade interna, devido à classificação dos setores nelas contidas, não permitia classificá-las imediatamente.

TABELA 3

Setores censitários considerando classificação do Índice de Moran Local para diferentes escalas de análise RM de Campinas - 2000

\begin{tabular}{lcccccc}
\hline \multirow{2}{*}{ Setores } & \multicolumn{3}{c}{ Classificação do Índice de Moran Local (\%) } & \multicolumn{2}{c}{ Total de setores } \\
\cline { 2 - 6 } & Não significante & Alto-Alto & Baixo-Baixo & Baixo-Alto & Alto-Baixo & censitários \\
\hline Setores censitários & 38,1 & 32,3 & 15,5 & 9,8 & 4,4 & 3.106 \\
Áreas de ponderação & 42,3 & 17,8 & 23,7 & 4,4 & 11,8 & 3.106 \\
\hline
\end{tabular}

Fonte: Elaboração dos autores.

\footnotetext{
10 Não se deve esquecer que as áreas de ponderação são agrupamentos de setores censitários.
} 
Para estas situações, a solução foi considerar que a nova classificação a ser adotada para as APs com heterogeneidade interna seria aquela registrada pelo conjunto de setores que representassem mais de $50 \%$ dos habitantes da AP, critério que pôde ser observado em todas as APs, sendo que, em cerca de $70 \%$ dos casos, o percentual representado pela população residente nos setores com a classificação que deveria prevalecer superou os $75 \%$.

Assim, com base nesses critérios, foi possível classificar todas as 111 áreas de ponderação, respeitando, da melhor forma possível, as indicações da homogeneidade socioeconômica obtidas a partir da análise dos setores censitários. Desse procedimento, resultaram $18 \mathrm{APs}$ na categoria Alto-Alto, 15 na Baixo-Baixo, cinco na Alto-Baixo e 73 não significantes, cuja localização pode ser vista no Mapa 3.11

Percebe-se que estas áreas estão mais concentradas em Campinas, o que não chama a atenção, pois o município detém quase a metade da população regional. No entanto, podem ser observadas outras

MAPA 3

Áreas de ponderação selecionadas para compor as zonas de segregação RM de Campinas - 2000

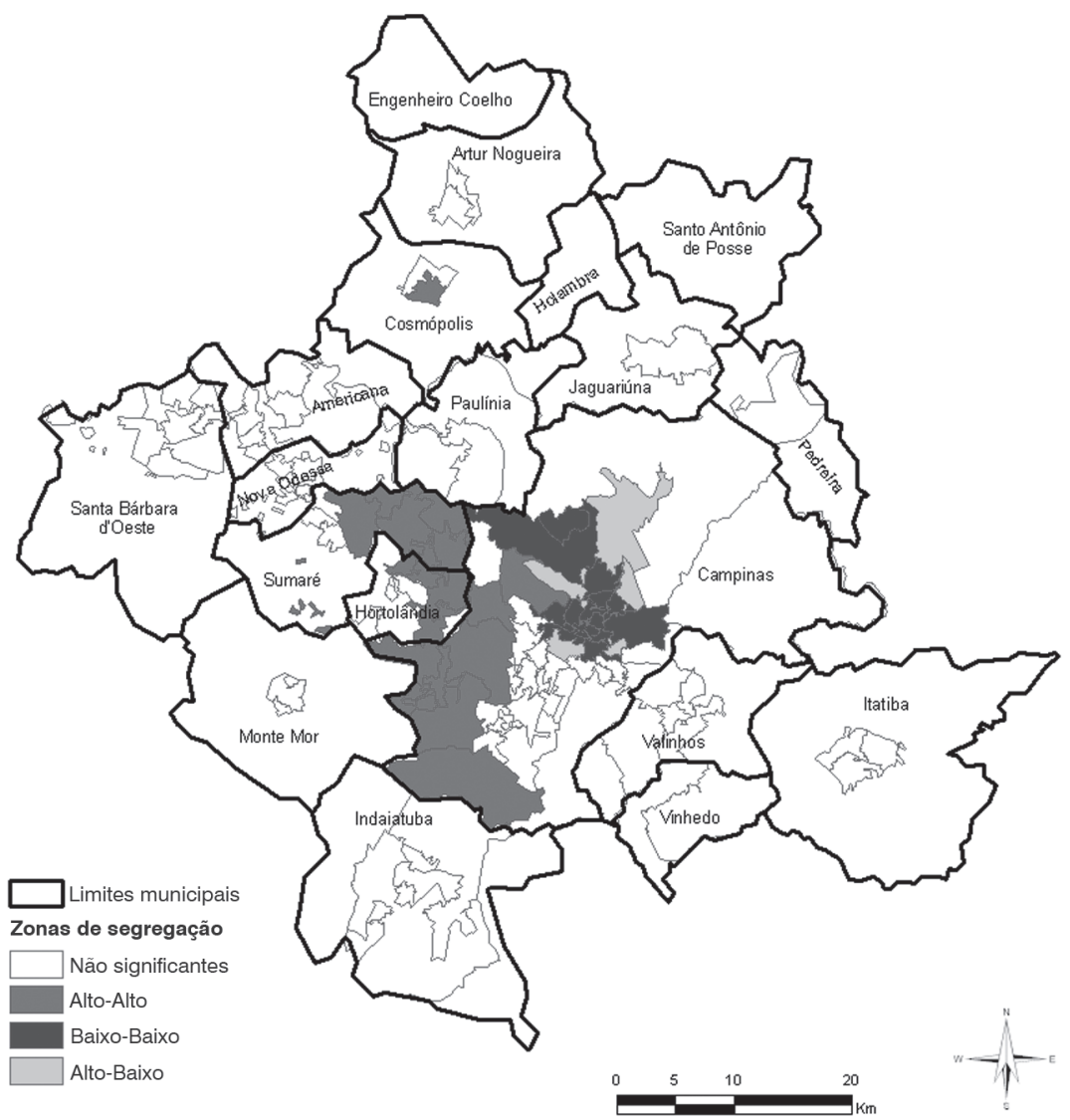

Fonte: IBGE. Malhas Digitais Municipais de 2001. Censo Demográfico de 2000.

\footnotetext{
11 Vale lembrar que o Mapa 3 traz informações apenas das áreas urbanas dos municípios metropolitanos, não constando ainda informações sobre os municípios de Engenheiro Coelho, Holambra e Santo Antônio de Posse, todos com tamanho populacional reduzido.
} 
áreas selecionadas (categoria Alto-Alto) em municípios periféricos, como Sumaré, Hortolândia e Cosmópolis, todos sabidamente com características de dormitório.

\section{Resultados: os impactos de segregação sobre a inserção laboral}

A presente análise será conduzida em duas etapas. A primeira compreende uma abordagem exploratória, em que se avaliam os diferenciais de comportamento dos indivíduos nas três dimensões relativas à inser- ção do mercado de trabalho (desemprego, formalidade e proteção social), segundo características sociodemográficas e posição no espaço regional a partir da localização destes nas distintas "zonas de segregação" construídas. Na segunda, formula-se um modelo multivariado, de maneira a tentar isolar o efeito da segregação sobre a inserção laboral, uma vez controladas as características individuais.

A Tabela 4 resume os resultados obtidos na análise descritiva. Assim, pode-se observar que, segundo a cor/raça da pessoa,

TABELA 4

População economicamente ativa com mais de 14 anos de idade, por indicadores de inserção laboral, segundo características sociodemográficas RM de Campinas - 2000

\begin{tabular}{|c|c|c|c|c|c|c|c|c|c|}
\hline \multirow{2}{*}{\multicolumn{2}{|c|}{$\begin{array}{c}\text { Características } \\
\text { sociodemográficas }\end{array}$}} & \multicolumn{2}{|c|}{$\begin{array}{l}\text { Condiçãa de } \\
\text { ocupação (\%) }\end{array}$} & \multicolumn{2}{|c|}{$\begin{array}{c}\text { Proteção social } \\
\text { (\%) }\end{array}$} & \multicolumn{2}{|c|}{$\begin{array}{l}\text { Formalidade } \\
\text { (\%) (1) }\end{array}$} & \multirow{3}{*}{$\begin{array}{c}\begin{array}{c}\text { Total de } \\
\text { ocupa- } \\
\text { dos }\end{array} \\
711.531\end{array}$} & \multirow{3}{*}{$\begin{array}{l}\text { Total } \\
835.527\end{array}$} \\
\hline & & \multirow{2}{*}{$\begin{array}{c}\begin{array}{c}\text { Com } \\
\text { trabalho }\end{array} \\
85,2\end{array}$} & \multirow{2}{*}{$\begin{array}{c}\begin{array}{c}\text { Sem } \\
\text { trabalho }\end{array} \\
14,8\end{array}$} & \multirow{2}{*}{$\frac{\text { Contribui }}{58,4}$} & \multirow{2}{*}{$\begin{array}{c}\begin{array}{c}\text { Não } \\
\text { contribui }\end{array} \\
41,6\end{array}$} & \multirow{2}{*}{$\begin{array}{c}\begin{array}{c}\text { Tem } \\
\text { carteira }\end{array} \\
55,4\end{array}$} & \multirow{2}{*}{$\begin{array}{c}\begin{array}{c}\text { Sem } \\
\text { carteira }\end{array} \\
44,6\end{array}$} & & \\
\hline \multirow{3}{*}{ Cor/raça } & Branca & & & & & & & & \\
\hline & Negra (preta+parda) & 79,4 & 20,6 & 50,0 & 50,0 & 57,2 & 42,8 & 225.286 & 283.798 \\
\hline & Outra & 83,2 & 16,8 & 54,9 & 45,1 & 48,7 & 51,3 & 14.948 & 17.967 \\
\hline \multirow{4}{*}{ Escolaridade } & Até 4 anos & 80,9 & 19,1 & 43,9 & 56,1 & 46,9 & 53,1 & 106.742 & 131.885 \\
\hline & 4 a 7 anos & 81,8 & 18,2 & 48,7 & 51,3 & 50,6 & 49,4 & 278.900 & 340.755 \\
\hline & 8 anos ou mais & 85,2 & 14,8 & 62,6 & 37,4 & 59,9 & 40,1 & 561.633 & 658.929 \\
\hline & Não determinada & 78,4 & 21,6 & 52,6 & 47,4 & 60,3 & 39,7 & 4.490 & 5.724 \\
\hline \multirow{3}{*}{ Estado civil } & Casado & 88,5 & 11,5 & 61,3 & 38,7 & 53,9 & 46,1 & 486.302 & 549.197 \\
\hline & Solteiro & 77,9 & 22,1 & 51,3 & 48,7 & 59,4 & 40,6 & 386.210 & 495.772 \\
\hline & Outros & 85,8 & 14,2 & 52,6 & 47,4 & 49,3 & 50,7 & 79.253 & 92.324 \\
\hline \multirow{3}{*}{ Idade } & 14 a 20 anos & 62,7 & 37,3 & 33,4 & 66,6 & 51,0 & 49,0 & 81.620 & 549.197 \\
\hline & 20 a 39 anos & 85,3 & 14,7 & 60,6 & 39,4 & 61,8 & 38,2 & 556.741 & 495.772 \\
\hline & 40 anos ou mais & 88,4 & 11,6 & 56,7 & 43,3 & 46,1 & 53,9 & 313.404 & 92.324 \\
\hline \multirow{2}{*}{ Sexo } & Masculino & 87,3 & 12,7 & 60,0 & 40,0 & 55,6 & 44,4 & 583.592 & 668.821 \\
\hline & Feminino & 78,6 & 21,4 & 50,9 & 49,1 & 55,9 & 44,1 & 368.173 & 468.472 \\
\hline \multirow{3}{*}{$\begin{array}{l}\text { Condição de } \\
\text { migração }\end{array}$} & Migr.intrametropolitano & 83,2 & 16,8 & 54,3 & 45,7 & 56,2 & 43,8 & 30.449 & 36.585 \\
\hline & Migr. externo RMC & 80,4 & 19,6 & 50,6 & 49,4 & 54,6 & 45,4 & 99.371 & 123.619 \\
\hline & Não-migrante & 84,1 & 15,9 & 57,0 & 43,0 & 55,9 & 44,1 & 821.946 & 977.089 \\
\hline \multirow{2}{*}{ Pendularidade } & Mesmo município & 81,4 & 18,6 & 53,2 & 46,8 & 53,2 & 46,8 & 798.254 & 980.063 \\
\hline & Outro município & 97,6 & 2,4 & 75,2 & 24,8 & 69,0 & 31,0 & 153.512 & 157.230 \\
\hline \multirow{4}{*}{$\begin{array}{l}\text { Zona de } \\
\text { segregação }\end{array}$} & Não significante & 84,1 & 15,9 & 56,3 & 43,7 & 56,2 & 43,8 & 660.056 & 785.236 \\
\hline & Alto-Alto & 78,0 & 22,0 & 49,7 & 50,3 & 56,9 & 43,1 & 145.947 & 187.008 \\
\hline & Baixo-Baixo & 89,2 & 10,8 & 64,7 & 35,3 & 50,8 & 49,2 & 107.428 & 120.487 \\
\hline & Alto-Baixo & 86,0 & 14,0 & 60,6 & 39,4 & 56,6 & 43,4 & 38.334 & 44.562 \\
\hline \multicolumn{2}{|l|}{ Total RMC } & 83,7 & 16,3 & 56,2 & 43,8 & 55,7 & 44,3 & 951.765 & 1.137 .293 \\
\hline
\end{tabular}

Fonte: IBGE. Censo Demográfico de 2000. Tabulações especiais Nepo/Unicamp.

(1) Refere-se ao total de ocupados. 
os brancos encontravam-se, em 2000, em melhor situação do que os negros tanto para os níveis de desemprego quanto para a proteção social, esta última bem mais elevada entre os brancos. Já no que se refere à formalização do trabalho, essa situação não era observada, chegando até a se inverter $(55,4 \%$ para os brancos contra $57,2 \%$ entre os negros ocupados). No entanto, esse dado não chega a surpreender, uma vez que, em termos das categorias socioocupacionais, ${ }^{12}$ pode-se constatar que os brancos apresentavam proporção maior de microempresários e profissionais que trabalham por conta-própria.

Quanto à educação, percebe-se uma correlação negativa entre os anos de estudo e o nível de desemprego e positiva com relação ao nível de proteção social (44\% da PEA com até quatro anos de estudo contribuía, contra $63 \%$ daqueles com oito ou mais anos de estudo), o mesmo acontecendo com relação à formalidade ( $47 \%$ da PEA ocupada com primário incompleto possuía carteira de trabalho assinada, contra $60 \%$ dos trabalhadores com ensino médio completo).

O estado civil da pessoa também se apresenta como uma variável que discrimina sensivelmente a participação do indivíduo no mercado de trabalho, com os casados apresentando, em 2000, um percentual de desemprego bem menor (11\%) do que os solteiros (22\%). Quanto à proteção social, os primeiros registravam 10 pontos percentuais a mais do que os segundos $(61 \%$ e $51 \%$, respectivamente, de contribuintes para a previdência), sendo que, da mesma maneira que o observado para os brancos e provavelmente pelas mesmas razões, os casados também detinham menor percentual de carteiras assinadas, sinalizando para uma menor formalização das relações de trabalho.

Para a idade das pessoas, também observa-se correlação negativa com o desemprego (37\% para aquelas com até 20 anos e 12\% para as de 40 anos ou mais), o mesmo ocorrendo em relação à proteção social ( $33 \%$ dos indivíduos com até 20 anos contribuíam para a previdência, contra 57\% daqueles com 40 anos ou mais). Quanto à formalidade no trabalho, o comportamento é mais variável: até os 40 anos, a maioria da PEA ocupada tinha carteira de trabalho assinada (chegando a 62\% entre 20 e 39 anos), percentual que se reduz para cerca de $46 \%$ depois dos 40 anos, refletindo os problemas enfrentados pelas pessoas em idades mais avançadas.

Com relação aos diferenciais por sexo, os resultados tampouco trazem novidades: os homens apresentavam menor desemprego (13\%) do que as mulheres (21\%); e $60 \%$ deles contribuíam para a previdência, contra $51 \%$ de mulheres. Já no caso da proteção social, não se observam grandes variações, uma vez que, para ambos os sexos, cerca de $56 \%$ da PEA ocupada possuía carteira de trabalho assinada em 2000.

Pode-se avaliar também a inserção dos indivíduos segundo sua condição migratória. Os dados mostram que, como seria de se esperar, o desemprego era um pouco menor entre os migrantes intrametropolitanos em comparação com os migrantes que provêm de fora da RMC (17\% e $20 \%$, respectivamente), sendo que sua proteção social era ligeiramente maior ( $54 \%$ dos intrametropolitanos contribuíam, contra $51 \%$ entre os de fora da RMC). Para a formalização das relações de trabalho, não se percebe diferença significativa.

Como já prenunciado, todos os indicadores apresentaram melhores resultados para os não-migrantes em comparação aos migrantes, sejam eles intrametropolitanos ou externos, fato que ajuda a corroborar a hipótese a respeito do impacto da condição migratória sobre a inserção produtiva do indivíduo.

Ainda com relação à mobilidade espacial, pode-se avaliar o comportamento das pessoas segundo a condição de pendularidade. Nesse caso, os dados da Tabela 5 também não deixam dúvidas de que aqueles que realizavam esse tipo de movimento cotidiano apresentavam diferenciais importantes em relação aos demais indivíduos.

\footnotetext{
12 Dados não apresentados.
} 
Assim, para as pessoas que realizavam o movimento pendular, o desemprego era obviamente muito baixo, assim como a proteção social é bem maior (75\% contribuíam para a previdência, contra $53 \%$ entre os não pendulares). Também no que se refere à formalidade no trabalho, $69 \%$ destas pessoas que realizavam o movimento, e que eram ocupados, possuíam carteira de trabalho assinada, contra $53 \%$ entre os que não realizavam este tipo de mobilidade. Por esses dados, embora não se possa estabelecer uma relação de causalidade, percebe-se que os movimentos cotidianos de um município ao outro parecem representar uma vantagem para aqueles que o realizam, garantindo uma inserção mais estável no mercado de trabalho.

Finalmente, quanto à localização dos indivíduos segundo as zonas de segregação, fica evidente que o local de residência parece estar fortemente associado ao acesso da pessoa ao mercado formal de trabalho, pois, enquanto nas zonas Alto-Alto o desemprego chegava a $22 \%$, nas Baixo-Baixo apenas $11 \%$ dos residentes enfrentavam esse problema. No que tange à proteção social, na primeira zona, $50 \%$ da PEA contribuía para a previdência, contra $65 \%$ na Baixo-Baixo. Também para a formalização no trabalho os diferenciais são evidentes segundo as distintas categorias de segregação analisadas: nas zonas classificadas como Alto-Alto, 57\% da PEA ocupada apresentava carteira de trabalho assinada, proporção que diminui para $51 \%$ nas Baixo-Baixo. Dados sobre as categorias socioocupacionais auxiliam a entender parte desse comportamento, mostrando que, nas zonas Baixo-Baixo, em 2000 , existia maior presença de empregadores, os quais, obviamente, não podem ser avaliados a partir desse indicador.

Outro resultado, menos óbvio e talvez mais interessante para os nossos propósitos, é obtido a partir da comparação entre as zonas Alto-Alto e Alto-Baixo, ou seja, entre aquelas com maior homogeneidade e concentração de pobres e aquelas onde os pobres estão próximos de pessoas com melhores condições de vida.

No que diz respeito tanto ao desemprego quanto à proteção social, os residentes em zonas menos homogêneas (Alto-Baixo) encontravam-se em melhores condições. A única variável em que não se notaram diferenças é a formalidade, o que sugere que a segregação não possui grande efeito quando o indivíduo está inserido no mercado de trabalho.

Deve-se reconhecer que essas associações identificadas não poderiam ser tratadas como indicações inequívocas do efeito da segregação sobre a possibilidade e forma de inserção do indivíduo no mercado de trabalho. Tem-se consciência de que estabelecer uma relação causal apenas a partir desses dados seria temerário, haja vista que é também muito razoável pensar que, da mesma forma que a localização pode ter efeito sobre essa inserção, o contrário também pode ocorrer, ou seja, o fato de estar bem ou mal colocado em termos laborais pode ter implicações decisivas sobre a determinação do local onde o indivíduo reside ou irá residir na região.

Responder a essa disjuntiva não é fácil e exigiria novos enfoques e, sobretudo, outras fontes de dados e metodologias de investigação, como, por exemplo, pesquisas qualitativas. No entanto, diante das várias evidências obtidas na literatura sobre o efeito que certas características do lugar podem ter sobre o comportamento das pessoas, é possível considerar, com alguma segurança, que os dados aqui analisados são mais um indício para sustentar esse tipo de argumentação.

Resolvido, ou ao menos amainado, esse impasse teórico, ainda restaria considerar que as indicações até aqui obtidas não são suficientemente robustas, tendo em vista as relações existentes entre o lugar de residência dos indivíduos e suas características socioeconômicas e demográficas. Nesse sentido, há que se buscar uma forma de isolar o efeito da segregação, controlando, em um modelo, as demais características individuais que, como se mostrou, possuem claro impacto sobre o acesso ao mercado de trabalho.

O modelo estatístico multivariado escoIhido para esse fim foi a regressão logística, que tem como principal objetivo produzir um modelo de predição de probabilidades la- 
tentes a partir de variáveis explicativas. Esta técnica diferencia-se de outros métodos de estimação por utilizar variáveis binomiais categóricas como variáveis de resposta, e por ser mais flexível quanto aos pressupostos de variância e distribuição dos erros. Trata-se, portanto, de um modelo de regressão para variáveis dependentes binomialmente distribuídas, permitindo modelar a probabilidade de um evento ocorrer a partir da ocorrência de outros fatores (AGRESTI, 1996).

Os parâmetros da regressão logística proposta foram estimados utilizando-se o pacote estatístico SAS (Statistical Analysis System). ${ }^{13}$ A partir da aplicação desse modelo, será possível conhecer o efeito individual de cada uma das variáveis sociodemográficas e de localização sobre os três aspectos relativos à inserção do indivíduo no mercado de trabalho (empregabilidade, formalidade e proteção social), uma vez controlados os efeitos das demais variáveis.

As categorias utilizadas para cada variável, assim como aquelas utilizadas como referência no modelo, são as seguintes:

- cor/raça: branca, negra (controle) e outra;

- escolaridade (em anos de estudo): até 4 anos (controle), de 4 a 8 anos e 8 anos ou mais;

- estado civil: casado, solteiro (controle) e outro;

- idade: até 20 anos (controle), de 20 a 39 anos e 40 anos ou mais;

- migração: migrante intrametropolitano com 0 a 2 anos de residência no município, migrante intrametropolitano com 3 a 5 anos de residência no município, migrante externo com 0 a 2 anos de residência no município, migrante externo com 3 a 5 anos de residência no município e não-migrante (controle);
- composição migratória da AP: até $10 \%, 10 \%$ a $30 \%$ e mais de $30 \%$ (controle) de migrantes com 0 a 9 anos de residência no município;

- pendularidade: mesmo município (controle), outro município;

- sexo: masculino e feminino (controle);

- zona de segregação: Alto-Alto, Baixo-Baixo, Alto-Baixo e não significante (controle).

O primeiro modelo foi ajustado tendo como variável dependente o nível de emprego para as pessoas economicamente ativas maiores de 14 anos. ${ }^{14}$

Como se observa na Tabela 5, os efeitos das variáveis sociodemográficas mostramse coerentes com o que se esperava: maior probabilidade de estar empregado para as pessoas brancas; da mesma forma a probabilidade aumenta para os indivíduos com mais de oito anos de estudo, para os casados, para os jovens e adultos (mais de 20 anos de idade) e para os homens.

Especificamente no que se refere à migração, ${ }^{15}$ nossa hipótese de que o migrante intrametropolitano deveria encontrar-se em melhores condições do que o migrante externo parece confirmar-se ao menos em relação ao migrante muito recente (menos de dois anos de residência). De fato, essa última categoria é a única que apresenta efeito significativo, ou seja, diferenças em comparação ao comportamento do "nãomigrante", utilizado como categoria de referência. Nesse caso, percebe-se que os migrantes externos recentemente chegados à região apresentam probabilidade $20 \%$ menor de estarem empregados (Tabela 5).

De qualquer forma, o que mais interessa para efeitos desse estudo é destacar os resultados relativos à variável de segregação socioespacial (zona de segregação). Nesse

\footnotetext{
13 Mais informações podem ser obtidas em Agresti (1996).

14 Este modelo responde por aproximadamente $62 \%$ das pessoas, tem um coeficiente de aderência de $26 \%$ e uma taxa de resposta de até $60 \%$ nos melhores decis, sendo, portanto, um modelo aceitável.

15 Nesse modelo não foi incluída a condição de pendularidade, uma vez que a chance de um indivíduo que realiza tal movimento, maior de 14 anos, ser empregado é muito grande, tendo em vista a forma como a informação foi captada no Censo. Assim, não faria muito sentido compará-lo com aquele que não faz esse tipo de movimento.
} 
TABELA 5

Resultados do modelo logístico tendo o nível de emprego como variável dependente, segundo características sociodemográficas RM de Campinas - 2000

\begin{tabular}{|c|c|c|c|c|c|c|c|}
\hline \multicolumn{2}{|c|}{ Características sociodemográficas } & \multirow{2}{*}{$\begin{array}{c}\text { Estimador } \\
-0,3505\end{array}$} & \multirow{2}{*}{$\begin{array}{c}\begin{array}{c}\text { Erro } \\
\text { padrão }\end{array} \\
0,0487\end{array}$} & \multirow{2}{*}{$\begin{array}{c}\begin{array}{c}\text { Wald } \\
\text { Chi-square }\end{array} \\
51,80\end{array}$} & \multirow{2}{*}{$\begin{array}{c}\begin{array}{c}\mathrm{Pr}> \\
\text { Chi-square }\end{array} \\
<, 0001\end{array}$} & \multicolumn{2}{|l|}{$\exp (E s t)$} \\
\hline Intercepto & & & & & & 0,704 & $\star \star * *$ \\
\hline \multirow{2}{*}{ Cor/raça } & Branca & 0,1373 & 0,0315 & 19,03 & $<, 0001$ & 1,147 & $* \star *$ \\
\hline & Outra & $-0,0147$ & 0,0592 & 0,06 & 0,8044 & 0,985 & \\
\hline \multirow{2}{*}{ Escolaridade } & 4 a 7 anos & $-0,0792$ & 0,0175 & 20,38 & $<, 0001$ & 0,924 & $\star \star \star *$ \\
\hline & 8 anos ou mais & 0,2777 & 0,0172 & 261,65 & $<, 0001$ & 1,320 & $* \star *$ \\
\hline \multirow{2}{*}{ Estado civil } & Casado & 0,1842 & 0,0185 & 99,53 & $<, 0001$ & 1,202 & *** \\
\hline & Outro & 0,0884 & 0,0282 & 9,83 & 0,0017 & 1,092 & ** \\
\hline \multirow{2}{*}{ Idade } & 20 a 39 anos & 0,3252 & 0,0157 & 427,14 & $<, 0001$ & 1,384 & $* \star *$ \\
\hline & 40 anos ou mais & 0,4298 & 0,0215 & 399,74 & $<, 0001$ & 1,537 & $* * *$ \\
\hline \multirow{2}{*}{$\begin{array}{l}\text { Migrantes na área de } \\
\text { ponderação }\end{array}$} & $<10 \%$ & $-0,0178$ & 0,0453 & 0,15 & 0,6948 & 0,982 & \\
\hline & $10 \%$ a $30 \%$ & 0,0139 & 0,0247 & 0,32 & 0,5743 & 1,014 & \\
\hline \multirow{4}{*}{ Migração } & Intra 0 a 2 anos & $-0,0129$ & 0,0692 & 0,03 & 0,8525 & 0,987 & \\
\hline & Intra 3 a 5 anos & 0,1020 & 0,0795 & 1,65 & 0,1991 & 1,107 & \\
\hline & Externo 0 a 2 anos & $-0,2168$ & 0,0434 & 24,98 & $<, 0001$ & 0,805 & $* * *$ \\
\hline & Externo 3 a 5 anos & 0,0514 & 0,0491 & 1,10 & 0,2953 & 1,053 & \\
\hline \multirow[t]{2}{*}{ Sexo } & Masculino & 0,3379 & 0,0114 & 882,46 & $<, 0001$ & 1,402 & $* * *$ \\
\hline & Alto-Alto & $-0,3293$ & 0,0282 & 136,47 & $<, 0001$ & 0,719 & $\star \star \star *$ \\
\hline \multirow[t]{2}{*}{ Zona de segregação } & Baixo-Baixo & 0,2659 & 0,0340 & 61,15 & $<, 0001$ & 1,305 & $\star \star \star *$ \\
\hline & Alto-Baixo & 0,0605 & 0,0487 & 1,54 & 0,2141 & 1,062 & \\
\hline
\end{tabular}

Fonte: IBGE. Censo Demográfico de 2000. Análises estatísticas realizadas pelos autores.

Nota: ${ }^{* \star *} \mathrm{p}$-val $<0,001 ;{ }^{\star *} \mathrm{p}$-val $<0,05 ;{ }^{*} \mathrm{p}$-val $<0,1$.

caso, o modelo mostra que residir nas áreas classificadas como Baixo-Baixo (ou seja, alta concentração de pessoas mais abastadas) aumentaria em $30,5 \%$ a chance de fugir do desemprego; entretanto, esta probabilidade se reduz em $28,1 \%$ quando se trata da residência com alta concentração de pobreza (Alto-Alto). Deve-se ressaltar também o fato de a categoria Alto-Baixo não ter apresentado efeito significativo, sugerindo que, em relação às zonas mais heterogêneas (nãosignificantes), ambas apresentariam efeitos similares sobre a probabilidade de emprego, o que leva a refletir sobre o possível impacto positivo, na população de baixa renda, do fato de este segmento residir próximo à população de alta renda.

Quanto à contribuição para a previdência social, a Tabela 6 mostra que a educação tem peso ainda maior do que o desemprego. ${ }^{16}$ De fato, um indivíduo com oito ou mais anos de estudo teria sua chance de contribuir para a previdência social aumentada em $57,9 \%$.

Também teriam as probabilidades incrementadas as pessoas com idade entre 20 e 39 anos $(48,0 \%)$ e do sexo masculino $(20,7 \%)$. No caso da pendularidade, a pessoa que realiza tal movimento tem grande vantagem (66,2\% maior) sobre a que não realiza. Nas demais variáveis sociodemográficas, as diferenças são bem menos acentuadas. Esse resultado sugere que a pendularidade estaria ligada à inserção em empregos mais estáveis e/ou formalizados.

Os efeitos da migração neste modelo mostram novamente o impacto da condição de migrante recente sobre a contribuição

\footnotetext{
${ }^{16}$ Este modelo responde por aproximadamente $62 \%$ das pessoas, tem um coeficiente de aderência de $25 \%$ e uma taxa de resposta de até $50 \%$ nos melhores decis, sendo assim um modelo razoável.
} 
para a previdência. Tanto para os intrametropolitanos quanto para os externos, o fato de residirem há menos de dois anos no município lhes reduz a probabilidade de ter essa proteção social quando comparados aos não-migrantes. No entanto, o que mais chama a atenção é que os migrantes externos mais antigos ( 3 a 5 anos de residência) registraram uma probabilidade $13 \%$ maior de estar nessa condição do que os nãomigrantes e, portanto, também com relação aos intrametropolitanos na mesma situação. Uma explicação para esse fato requereria uma análise mais detalhada sobre as características de ambos os migrantes, uma vez que a migração intrametropolitana na RMC não é o fator central da produção do espaço metropolitano, em particular das periferias onde a migração externa tem grande peso, chegando a representar, no conjunto da região, quase $78 \%$ da migração recebida (CUNHA, et. al., 2006, p.347).

O lugar onde moram as pessoas apresenta efeito significativo também no caso da proteção social. Assim, residir em uma zona Alto-Alto (alta concentração de pobreza) implica uma redução de $21,7 \%$ nas chances de contribuição para a previdência social, enquanto viver em zonas com maior concentração de riqueza (Baixo-Baixo) significa um aumento de 13,5\%. Observa-se aqui que o pobre parece beneficiar-se do fato de residir em zonas também ocupadas por população de mais alta renda (zonas Alto-Baixo), já que a probabilidade cresce cerca de $12,6 \%$.

Foram ajustados, por último, modelos para variáveis relativas à condição de formalidade no mercado de trabalho. Tentou-se, a partir de um modelo logístico, também

TABELA 6

Resultados do modelo logístico tendo a contribuição para a previdência social como variável dependente, segundo características sociodemográficas RM de Campinas - 2000

\begin{tabular}{|c|c|c|c|c|c|c|c|}
\hline \multicolumn{2}{|c|}{ Características sociodemográficas } & \multirow{2}{*}{$\begin{array}{c}\text { Estimador } \\
-0,3087 \\
\end{array}$} & \multirow{2}{*}{$\begin{array}{c}\begin{array}{c}\text { Erro } \\
\text { padrão }\end{array} \\
0,0321\end{array}$} & \multirow{2}{*}{$\begin{array}{c}\begin{array}{c}\text { Wald } \\
\text { Chi-square }\end{array} \\
92,52\end{array}$} & \multirow{2}{*}{$\begin{array}{c}\text { Pr > } \\
\text { Chi-square } \\
<, 0001\end{array}$} & \multicolumn{2}{|l|}{$\exp (E s t)$} \\
\hline Intercepto & & & & & & 0,734 & $* \star *$ \\
\hline \multirow{2}{*}{ Cor/raça } & Branca & 0,0970 & 0,0200 & 23,53 & $<, 0001$ & 1,102 & 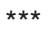 \\
\hline & Outra & $-0,0730$ & 0,0377 & 3,76 & 0,0524 & 0,930 & * \\
\hline \multirow{2}{*}{ Escolaridade } & 4 a 7 anos & $-0,1294$ & 0,0112 & 132,57 & $<, 0001$ & 0,879 & $\star \star \star *$ \\
\hline & 8 anos ou mais & 0,4565 & 0,0109 & 1748,61 & $<, 0001$ & 1,579 & $* \star *$ \\
\hline \multirow{2}{*}{ Estado civil } & Casado & 0,1543 & 0,0114 & 184,37 & $<, 0001$ & 1,167 & $\star \star \star *$ \\
\hline & Outro & $-0,0543$ & 0,0175 & 9,69 & 0,0019 & 0,947 & ** \\
\hline \multirow{2}{*}{ Idade } & 20 a 39 anos & 0,3919 & 0,0105 & 1394,27 & $<, 0001$ & 1,480 & $\star \star \star *$ \\
\hline & 40 anos ou mais & 0,2598 & 0,0137 & 360,24 & $<, 0001$ & 1,297 & $\star \star *$ \\
\hline \multirow{2}{*}{$\begin{array}{l}\text { Migrantes na área } \\
\text { de ponderação }\end{array}$} & $<10 \%$ & 0,1141 & 0,0284 & 16,14 & $<, 0001$ & 1,121 & $\star \star *$ \\
\hline & 10 a $30 \%$ & 0,0831 & 0,0155 & 28,84 & $<, 0001$ & 1,087 & $\star \star \star$ \\
\hline \multirow{4}{*}{ Migração } & Intra 0 a 2 anos & $-0,1265$ & 0,0443 & 8,16 & 0,0043 & 0,881 & ** \\
\hline & Intra 3 a 5 anos & $-0,0677$ & 0,0521 & 1,69 & 0,1943 & 0,935 & \\
\hline & Externo 0 a 2 anos & $-0,1317$ & 0,0287 & 21,08 & $<, 0001$ & 0,877 & $\star \star \star *$ \\
\hline & Externo 3 a 5 anos & 0,1192 & 0,0317 & 14,18 & 0,0002 & 1,127 & $\star \star \star *$ \\
\hline Pendularidade & Outro munic. & 0,5079 & 0,0115 & 1957,21 & $<, 0001$ & 1,662 & $\star \star \star$ \\
\hline Sexo & Masculino & 0,1877 & 0,0072 & 675,15 & $<, 0001$ & 1,207 & $\star \star \star *$ \\
\hline \multirow{3}{*}{$\begin{array}{l}\text { Zona de } \\
\text { segregação }\end{array}$} & Alto-Alto & $-0,2447$ & 0,0183 & 179,00 & $<, 0001$ & 0,783 & $* \star *$ \\
\hline & Baixo-Baixo & 0,1267 & 0,0203 & 38,76 & $<, 0001$ & 1,135 & $* * *$ \\
\hline & Alto-Baixo & 0,1189 & 0,0303 & 15,38 & $<, 0001$ & 1,126 & $\star \star \star *$ \\
\hline
\end{tabular}

Fonte: IBGE. Censo Demográfico de 2000. Análises estatísticas realizadas pelos autores.

Nota: ${ }^{* \star *} p$-val $<0,001 ;{ }^{* \star} p$-val $<0,05 ;{ }^{*} p$-val $<0,1$. 
investigar os efeitos das variáveis utilizadas nesse estudo sobre a formalidade no trabalho, expressa em termos da posse de carteira assinada para ocupados tanto com ensino fundamental, quanto com ensino médio ou superior. ${ }^{17}$

Os dados da Tabela 7 mostram novamente maiores probabilidades para as pessoas economicamente ativas com idade entre 20 e 39 anos (53,5\% a mais). ${ }^{18}$

Nesse caso específico, passa a ter significância estatística a variável relativa à composição migratória das áreas analisadas. Assim, pessoas residindo em APs com até $10 \%$ de migrantes recentes pos- suem $53 \%$ mais de chance de uma formalidade no mercado de trabalho do que os moradores em APs com mais de $30 \%$ de migrantes recentes, fato que sugere que a convivência com pessoas mais antigas ou não-migrantes pode implicar vantagens em termos da formalização do trabalho. Aliás, esse resultado mostra-se compatível com o efeito da variável tipo de migrante, que, como será mostrado a seguir, aponta para o efeito negativo de ser migrante recente.

Comparando-se a migração intrametropolitana e a externa à RM, novamente as conclusões são semelhantes às obtidas no modelo anterior, ou seja, parece haver,

TABELA 7

Resultados do modelo logístico tendo a posse de carteira assinada no trabalho como variável dependente, em termos das pessoas ocupadas com ensino fundamental, segundo características sociodemográficas RM de Campinas - 2000

\begin{tabular}{|c|c|c|c|c|c|c|c|}
\hline \multicolumn{2}{|c|}{ Características sociodemográficas } & \multirow{2}{*}{$\begin{array}{c}\text { Estimador } \\
0,2452\end{array}$} & \multirow{2}{*}{$\begin{array}{c}\begin{array}{c}\text { Erro } \\
\text { padrão }\end{array} \\
0,0429\end{array}$} & \multirow{2}{*}{$\begin{array}{c}\begin{array}{c}\text { Wald } \\
\text { Chi-square }\end{array} \\
32,72\end{array}$} & \multirow{2}{*}{$\begin{array}{c}\text { Pr }> \\
\text { Chi-square } \\
<, 0001\end{array}$} & \multicolumn{2}{|l|}{$\exp (E s t)$} \\
\hline Intercepto & & & & & & 1,278 & *** \\
\hline \multirow{2}{*}{ Cor/raça } & Branca & 0,1526 & 0,0282 & 29,30 & $<, 0001$ & 1,165 & $* * *$ \\
\hline & Outra & $-0,0532$ & 0,0535 & 0,99 & 0,3207 & 0,948 & \\
\hline \multirow{2}{*}{ Estado civil } & Casado & 0,0215 & 0,0149 & 2,07 & 0,1500 & 1,022 & \\
\hline & Outro & $-0,1835$ & 0,0230 & 63,85 & $<, 0001$ & 0,832 & *** \\
\hline \multirow{2}{*}{ Idade } & 20 a 39 anos & 0,4288 & 0,0145 & 873,95 & $<, 0001$ & 1,535 & $* * *$ \\
\hline & 40 anos ou mais & $-0,3913$ & 0,0178 & 481,59 & $<, 0001$ & 0,676 & *** \\
\hline \multirow{2}{*}{$\begin{array}{l}\text { Migrantes na área de } \\
\text { ponderação }\end{array}$} & $<10 \%$ & 0,4253 & 0,0391 & 118,48 & $<, 0001$ & 1,530 & $* * *$ \\
\hline & $10 \%$ a $30 \%$ & $-0,0072$ & 0,0211 & 0,11 & 0,7354 & 0,993 & \\
\hline \multirow{4}{*}{ Migração } & Intra 0 a 2 anos & $-0,1959$ & 0,0567 & 11,94 & 0,0006 & 0,822 & $\star * *$ \\
\hline & Intra 3 a 5 anos & 0,0213 & 0,0678 & 0,10 & 0,7535 & 1,022 & \\
\hline & Externo 0 a 2 anos & $-0,0626$ & 0,0383 & 2,68 & 0,1017 & 0,939 & \\
\hline & Externo 3 a 5 anos & 0,1296 & 0,0414 & 9,80 & 0,0017 & 1,138 & ** \\
\hline Pendularidade & Outro munic. & 0,4648 & 0,0140 & 1105,72 & $<, 0001$ & 1,592 & $\star * *$ \\
\hline \multirow[t]{2}{*}{ Sexo } & Masculino & $-0,0559$ & 0,0098 & 32,64 & $<, 0001$ & 0,946 & *** \\
\hline & Alto-Alto & $-0,3315$ & 0,0245 & 183,69 & $<, 0001$ & 0,718 & $\star * *$ \\
\hline \multirow[t]{2}{*}{ Zona de segregação } & Baixo-Baixo & 0,5851 & 0,0310 & 356,14 & $<, 0001$ & 1,795 & *** \\
\hline & Alto-Baixo & $-0,1111$ & 0,0408 & 7,43 & 0,0064 & 0,895 & ** \\
\hline
\end{tabular}

Fonte: IBGE. Censo Demográfico de 2000. Análises estatísticas realizadas pelos autores.

Nota: ${ }^{* \star *} \mathrm{p}$-val $<0,001 ;{ }^{* *} \mathrm{p}$-val $<0,05 ;{ }^{*} \mathrm{p}$-val $<0,1$.

\footnotetext{
17 É importante frisar que esta separação em dois modelos visa eliminar possíveis distorções causadas pelo fato de as pessoas com maior escolaridade não possuírem emprego formal em função da sua própria ocupação, como se observa nos casos de profissionais liberais, por exemplo.

18 Este modelo responde para aproximadamente $61 \%$ das pessoas, tem um coeficiente de aderência de $24 \%$ e uma taxa de resposta de até $55 \%$ nos melhores decis, parâmetros que sugerem que o modelo seja aceitável.
} 
em relação à população aqui considerada não-migrante, uma vantagem dos migrantes externos mais antigos (com 3 a 5 anos de residência no município), já que estes apresentaram quase $14 \%$ a mais de chance de possuírem carteira de trabalho assinada; o inverso ocorre com os migrantes recentes, sejam eles externos ou intrametropolitanos.

No caso da variável pendularidade, o modelo mostra que realizar esse tipo de movimento incrementa a chance $(59,2 \%)$ de possuir carteira de trabalho assinada em relação às pessoas que não realizam, resultado que, mais uma vez, reforça a ideia de que o fenômeno da pendularidade está associado, de alguma forma, a melhores condições de inserção, fato já apontado em outros estudos (SOBREIRA; CUNHA, 2007).

Destaca-se o efeito da localização sobre a variável dependente em pauta. Como mostram os dados da Tabela 7 , os que moram em áreas de melhor condição social (Baixo-Baixo) possuem 79,5\% a mais de chances de conseguir um trabalho com carteira assinada, enquanto os residentes em áreas de pior condição social (Alto-Alto) têm uma probabilidade $28,2 \%$ menor de trabalhar com carteira assinada. $O$ estrato Alto-Baixo também apresenta redução na chance de conseguir emprego com carteira assinada, de $10,5 \%$.

Finalmente, a Tabela 8 traz, para a mesma variável dependente, os resultados do modelo logístico para aqueles pertencentes ao segundo subgrupo de pessoas ocupadas, ou seja, aqueles com ensino médio ou superior.

Percebe-se, a partir desses dados, que os efeitos com significância estatística ocorrem nas variáveis cor, estado civil, idade da pessoa, condição migratória e de pendularidade e residência segundo a zona

TABELA 8

Resultados do modelo logístico tendo a posse de carteira assinada no trabalho como variável dependente, em termos das pessoas ocupadas com ensino médio ou superior, segundo características sociodemográficas RM de Campinas - 2000

\begin{tabular}{|c|c|c|c|c|c|c|c|}
\hline \multicolumn{2}{|c|}{ Características sociodemográficas } & \multirow{2}{*}{$\begin{array}{c}\text { Estimador } \\
-0,2647\end{array}$} & \multirow{2}{*}{$\begin{array}{c}\begin{array}{c}\text { Erro } \\
\text { padrão }\end{array} \\
0,0492\end{array}$} & \multirow{2}{*}{$\begin{array}{c}\begin{array}{c}\text { Wald } \\
\text { Chi-square }\end{array} \\
28,90\end{array}$} & \multirow{2}{*}{$\begin{array}{c}\begin{array}{c}\mathrm{Pr}> \\
\text { Chi-square }\end{array} \\
<, 0001\end{array}$} & \multicolumn{2}{|l|}{$\exp (E s t)$} \\
\hline Intercepto & & & & & & 0,767 & *** \\
\hline \multirow{2}{*}{ Cor/raça } & Branca & $-0,0971$ & 0,0311 & 9,77 & 0,0018 & 0,907 & ** \\
\hline & Outra & $-0,4449$ & 0,0579 & 58,94 & $<, 0001$ & 0,641 & $\star * *$ \\
\hline \multirow{2}{*}{ Estado civil } & Casado & $-0,0690$ & 0,0186 & 13,73 & 0,0002 & 0,933 & $\star \star \star *$ \\
\hline & Outro & 0,0190 & 0,0291 & 0,43 & 0,5127 & 1,019 & \\
\hline \multirow{2}{*}{ Idade } & 20 a 39 anos & 0,2538 & 0,0171 & 219,53 & $<, 0001$ & 1,289 & *** \\
\hline & 40 anos ou mais & 0,0600 & 0,0220 & 7,45 & 0,0064 & 1,062 & ** \\
\hline \multirow{2}{*}{$\begin{array}{l}\text { Migrantes } \\
\text { na área de } \\
\text { ponderação }\end{array}$} & $<10 \%$ & $-0,1483$ & 0,0430 & 11,89 & 0,0006 & 0,862 & $* \star *$ \\
\hline & $10 \%$ a $30 \%$ & 0,0500 & 0,0238 & 4,39 & 0,0361 & 1,051 & $* *$ \\
\hline \multirow{4}{*}{ Migração } & Intra 0 a 2 anos & $-0,0531$ & 0,0738 & 0,52 & 0,4718 & 0,948 & \\
\hline & Intra 3 a 5 anos & $-0,2328$ & 0,0849 & 7,52 & 0,0061 & 0,792 & ** \\
\hline & Externo 0 a 2 anos & $-0,0987$ & 0,0465 & 4,51 & 0,0337 & 0,906 & ** \\
\hline & Externo 3 a 5 anos & 0,2154 & 0,0511 & 17,76 & $<, 0001$ & 1,240 & $\star * *$ \\
\hline Pendularidade & Outro munic. & 0,2265 & 0,0161 & 198,84 & $<, 0001$ & 1,254 & $* * *$ \\
\hline Sexo & Masculino & 0,0451 & 0,0116 & 15,09 & 0,0001 & 1,046 & $* * *$ \\
\hline \multirow{3}{*}{$\begin{array}{l}\text { Zona de } \\
\text { segregação }\end{array}$} & Alto-Alto & 0,4378 & 0,0311 & 198,09 & $<, 0001$ & 1,549 & $* * *$ \\
\hline & Baixo-Baixo & $-0,6950$ & 0,0288 & 582,88 & $<, 0001$ & 0,499 & $* * *$ \\
\hline & Alto-Baixo & 0,0698 & 0,0465 & 2,26 & 0,1331 & 1,072 & \\
\hline
\end{tabular}

Fonte: IBGE. Censo Demográfico de 2000. Análises estatísticas realizadas pelos autores.

Nota: ${ }^{* * *} \mathrm{p}$-val $<0,001 ;{ }^{* *} \mathrm{p}-\mathrm{val}<0,05 ;{ }^{*} \mathrm{p}-\mathrm{val}<0,1$ 
de segregação. ${ }^{19} \mathrm{O}$ sexo e a composição migratória das áreas não apresentaram efeitos relevantes.

Assim, para esse grupo de pessoas, ter entre 20 e 39 anos aumenta em $28,9 \%$ a chance de uma formalidade em termos de posse de carteira de trabalho assinada, sendo que o fato de ter ultrapassado os 40 anos reduz essa chance em comparação aos menores de 20 anos.

Um resultado interessante do modelo e que certamente mereceria maior investigação e discussão é o fato de os negros com maior escolaridade, controladas todas as outras variáveis, não apresentarem diferença significativa em relação aos brancos no que se refere à posse de carteira assinada. Esse dado é sugestivo para refletir sobre o peso da educação e da condição ética/racial sobre a inserção da pessoa no mercado de trabalho.

A condição de pendularidade uma vez mais emerge como fator importante, assim como o maior tempo de residência dos migrantes externos. No primeiro caso, a probabilidade de ter um emprego formal é $25,4 \%$ maior para aqueles que trabalham em um município distinto de onde residem. Do mesmo modo, ser migrante externo mais antigo eleva essa chance em $24 \%$ com relação ao não-migrante e ainda mais em comparação aos migrantes recém-chegados.

Novamente, o resultado que mais nos interessa diz respeito ao efeito da localização sobre a formalidade das pessoas com maior nível escolar. Diferentemente do modelo anterior, aqueles que vivem em áreas mais segregadas e pobres, mas com bom nível educacional, possuem uma probabilidade 55\% maior de conseguirem um emprego com carteira assinada, em relação aos que vivem em zonas com maior mescla social, ao passo que os residentes em áreas de alta renda apresentam uma chance $50 \%$ menor. Chama a atenção também o fato de que viver em uma área de concentração de pobreza, mas com um entorno diferenciado
(Alto-Baixo), também dá vantagens aos residentes.

Em suma, considerando os resultados dos quatro modelos ajustados, pode-se dizer que, mesmo controlando variáveis importantes e chaves (como sexo, idade e educação), para a inserção no mercado de trabalho, o lugar de residência do indivíduo parece assumir um papel relevante. $\mathrm{Na}$ verdade, a força desse fator fica ainda mais visível quando o impacto da educação é reduzido de forma significativa, como no último modelo avaliado (carteira assinada para pessoa com ensino médio ou superior); mesmo nesse caso, as chances de alcançar uma situação mais estável se reduzem gritantemente para as pessoas residentes nas zonas mais segregadas e pobres da região. Além disso, as melhores condições daqueles pobres residentes em área cercada por população de mais alta renda também ratificam não ser a questão de pobreza (e educação) o único elemento a ser considerado quando se analisa a inserção laboral das pessoas.

\section{Considerações finais}

Analisar e identificar de maneira inequívoca o efeito que a localização do indivíduo numa grande aglomeração urbana tem sobre o seu comportamento, suas vulnerabilidades e condições gerais de vida não é tarefa das mais simples. Se, por um lado, a literatura tem apontado mecanismos a partir dos quais isso se concretiza, por outro, os métodos de investigação e, sobretudo, os dados com que se trabalha nem sempre são suficientemente adequados para se chegar a conclusões definitivas.

Este é o caso do presente trabalho. Mesmo tendo sido feito um esforço empírico para isolar o efeito que distintas situações de segregação podem ter sobre algumas características relativas à inserção do indivíduo no mercado de trabalho, tem-se consciência que tanto a fonte (o Censo De-

\footnotetext{
19 Este modelo responde para aproximadamente $60 \%$ das pessoas, tem um coeficiente de aderência de $21 \%$ e uma taxa de resposta de até $40 \%$ nos melhores decis, parâmetros que sugerem que o modelo seja aceitável.
} 
mográfico) quanto a forma de caracterizar as distintas situações de segregação (zonas de segregação) padecem de limitações, tendo em vista a complexidade do problema. $\mathrm{Na}$ verdade, os resultados obtidos a partir do uso das informações censitárias, na melhor das hipóteses, poderiam ser utilizados como guias para suscitarem novas investigações e metodologias objetivando isolar os possíveis mecanismos que explicariam esse efeito.

De qualquer maneira, os dados aqui analisados sugeriram que diferentes localizações na região possuem, de fato, impactos significativos sobre a inserção no mercado de trabalho dos indivíduos. Os modelos ajustados para quatro variáveis dependentes - desemprego, proteção social, formalidade no trabalho para pessoas com baixa escolaridade e para aquelas com elevada educação - mostraram que, mesmo quando controladas variáveis sociodemográficas reconhecidamente importantes para explicar os fenômenos em questão, os efeitos da localização ainda permanecem significativos.

$\mathrm{Na}$ verdade, embora não fosse a principal motivação desse estudo, os resultados do modelo também sugeriram uma importante agenda de estudos, tendo em vista os efeitos estimados para variáveis como a composição migratória das áreas e a condição migratória e de pendularidade das pessoas. Sem dúvida que entender o porquê destes efeitos, pelo interesse que desperta em particular nos demógrafos, será matéria de investigações no futuro.

Com relação ao efeito de localização, deve-se destacar que, mais além das significativas diferenças encontradas entre a população das zonas de segregação extremas (categorias Alto-Alto e Baixo-Baixo), foi muito interessante o resultado obtido para aquelas zonas de residência da população pobre que se encontravam próximas das áreas habitadas pelos estratos de meIhor condição social na região (categoria Alto-Baixo). Nesse caso, as estimativas mostraram uma melhor condição dessa população em comparação com aquela residente em zonas de alta segregação de pobreza (categoria Alto-Alto). Na verdade, esse resultado reforça hipóteses como aquelas que consideram os "efeitos de rol", ou o menor isolamento social com mecanismos a partir dos quais as condições de vulnerabilidade da população mais pobre poderiam ser reduzidas.

Há que se reconhecer, por último, uma limitação teórico/metodológica que decorre do tipo de enfoque utilizado nesse estudo. Mesmo considerando-se as evidências de outros estudos, bem como as observações teóricas sobre os mecanismos que influenciariam no efeito do bairro sobre o comportamento do indivíduo, ao menos no caso da dimensão aqui analisada (o mercado de trabalho), sempre resta uma dúvida sobre a relação causal entre um e outro fenômeno. Afinal, será mesmo o fato de morar em áreas segregadas uma das causas da pior, ou melhor, inserção laboral? Não seria justamente essa melhor inserção que explicaria a localização do indivíduo no espaço regional? Além disso, não se pode esquecer que, nos países em desenvolvimento, em particular no Brasil, o mercado de trabalho é o principal meio para escapar da condição de pobreza, o que torna ainda mais complexa a identificação de uma relação de causalidade entre segregação e inserção produtiva.

Acreditamos que essa disjuntiva não é simples de ser respondida, sobretudo no caso do presente trabalho, que é centrado em dados do tipo transversal. É provável que estudos longitudinais fossem mais adequados para responder a esse tipo de questão, uma vez que seria possível avaliar melhor as situações que levariam o indivíduo a se localizar nessa ou naquela área de cidade, tendo em vista o seu histórico de inserção no mercado de trabalho.

Não obstante o anterior, estamos de acordo com os vários autores que apostam no efeito do lugar como um caminho promissor, sobretudo pelo que isso significaria em termos de proposição de políticas públicas. Ao que tudo indica, as características sociodemográficas não são suficientes para explicar a inserção do indivíduo no mercado de trabalho. Desta forma, o espaço, ou o que ele significa no processo de reprodução social, parece ser um elemento a ser sempre levado em conta. 


\section{Referências}

AGRESTI, A. An introduction to categorical data analysis. John Wiley and Sons, Inc., 1996.

ANSELIN, L. Local indicators of spatial association - LISA. Geographical Analysis, 27, p.93-115, 1995.

CASTELLS, M. A era da informação: economia, sociedade e cultura. $2^{a}$ ed. Vol. 1 A Sociedade em Rede. São Paulo: Paz e Terra, 1999.

CUNHA, E.M.G.P. Panorama actual de las condiciones socioeconomicas e demográficas de la población negra brasileña y sus consecuencias en la salud. In: IX JORNADAS ARGENTINAS DE ESTUDIOS DE POBLACIÓN. Anais... Córdoba, Argentina, 2007.

CUNHA, J.M.P. et al. Social segregation and academic achievement in state-run elementary schools in the municipality of Campinas, Brazil. Paper presented at Annual Meeting of the Population Association of America, New York, 2007.

CUNHA, J.M.P.; JIMÉNEZ, M.A. The process of cumulative disadvantage: concentration of poverty and the quality of public education in the Metropolitan Region of Campinas. Working paper presented at the Conference on Spatial Differentiation and Governance in the Americas, Austin, Texas, November 17-19, 2006.

CUNHA, J.M.P.; JAKOB, A.A.E.; JIMÉNEZ, M.A. The geography of opportunity: social segregation and its effects on public education in the Metropolitan Region of Campinas. Paper presented at Annual Meeting of the Population Association of America, Los Angeles, CA, 2006.

CUNHA, J.M.P.; JAKOB, A.A.E.; JIMÉNEZ, M.A.; TRAD, L.T. Expansão metropolitana, mobilidade espacial e segregação nos anos 90: o caso da Região Metropolitana de Campinas. In: CUNHA, J.M.P. (Ed.). Novas metrópoles paulistas: população, vulnerabilidade e segregação. Campinas: Nepo/Unicamp, 2006.
DEDECCA, C.S. O trabalho no Brasil do início do século XXI: metodologia e análise do Censo Demográfico 2000. Relatório de Pesquisa. Campinas: Instituto de Economia/ Unicamp, 2006.

DEDECCA, C.S.; BALTAR, P.E.A. Mercado de trabalho e informalidade nos anos $\mathbf{9 0}$. Campinas: Instituto de Economia/Unicamp, 1999. Mimeografado.

FLORES, C. Consequências da segregação residencial: teoria e métodos. In: CUNHA, J. M. P. (Org.). Novas metrópoles paulistas: população, vulnerabilidade e segregação. Campinas: Nepo/Unicamp, 2006.

GALSTER, G. C.; KILLEN, S. P. The geography of metropolitan opportunity: a recent reconnaissance and conceptual framework. Housing Policy Debate, 6, p. 7-43, 1995.

GALSTER, G. C.; MIKELSONS, M. The geography of metropolitan opportunity: a case study of neighborhood conditions confronting youth in Washington, DC. Housing Policy Debate, 6, p. 73-102, 1995.

HARVEY, D. Condição pós-moderna: uma pesquisa sobre as origens da mudança cultural. 14aㅡ ed. São Paulo: Loyola, 2005.

JENKS, C.; MAYER, S. The consequences of growing up in a poor neighborhood. In: LYNN, L.; MCGEARY, M.G.H. (Eds.). Inner-city poverty in the United States. Washington: National Academy Press, 1990.

KAZTMAN, R.; FILGUEIRA, F. As normas como bem público e privado: reflexões nas fronteiras do enfoque "ativos, vulnerabilidade e estrutura de oportunidades" (Aveo). In: CUNHA, J.M.P. (Org.). Novas metrópoles paulistas: população, vulnerabilidade e segregação. Campinas: Nepo/Unicamp, 2006.

KAZTMAN, R. Seducidos y abandonados: el aislamiento social de los pobres urbanos. Revista de la CEPAL, Santiago do Chile, n.75, p.171-189, dec.2001.

(Coord.). Activos y estructura de oportunidades. Estudios sobre las 
raíces de la vulnerabilidad social en Uruguay. Uruguay: PNUD-Uruguay e Cepal-Oficina de Montevideo, 1999.

KAZTMAN, R. et al. Vulnerabilidad, activos y exclusión social en Argentina y Uruguay. Santiago do Chile: OIT, 1999 (Documento de Trabajo, 107).

MASSEY, D.S.; DENTON, N.A. The dimensions of racial segregation. Social Forces, n.67, p.281-315, 1988.

PORTES, A. Latin American class structures: their composition and change during the last decade. Latin American Research Review, 20, p.7-39, 1985.

PORTES, A.; HOFFMAN, K. Latin American class structures: their composition and change during the neoliberal era. Latin American Research Review, v. 38, n. 1, p.41-82, February 2003.

PRETECEILLE, E. Divisão social e desigualdades: transformações recentes na metrópole parisiense. In: RIBEIRO, L.C. de $Q$. (Org.). O futuro das metrópoles: desigualdades e governança. Rio de Janeiro: Ed. Revan, 2000.

SABATINI, F. Medición de la segregación residencial: reflexiones metodológicas desde la ciudad latinoamericana. In: CÁCERES, F.; SABATINI, F. (Eds). Barrios cerrados en Santiago de Chile: entre la exclusión y la integración residencial. Cambridge, MA: Lincoln Institute of Land Policy, 2004.

SABATINI, F.; CÁCERES, F.; CERDA, J. Segregação residencial nas principais cidades chilenas: tendências das três últimas décadas e possíveis cursos de ação. Espaço \& Debates, n.45, p.60-74, 2004.
SABATINI, F.; SIERRALTA, C. Medição da segregação residencial: meandros teóricos e metodológicos e especificidade latino-americana. In: CUNHA, J.M.P. (Org.). No-vas metrópoles paulistas: população, vulnerabilidade e segregação. Campinas: Nepo/Unicamp, p. 169-195, 2006.

SAMPSON, R.J.; RAUDENBUSH, S.; EARLS, F. Neighborhoods and violente crime: a multilevel study of collective efficacy. Science, v. 277, n. 5.328, 1997.

SASSEN, S. The global city: New York, London, Tokyo. Princeton: Princeton Univ., 1991.

SOBREIRA, D.P.; CUNHA, J.M.P. A metrópole e seus deslocamentos populacionais cotidianos: o caso da mobilidade pendular na Região Metropolitana de Campinas em 2000. In: XII ENCONTRO NACIONAL DA ANPUR. Anais... Belém, Pará, 2007.

TORRES, H. da G.; FERREIRA, M.P.; GOMES, S. Educação e segregação social: explorando o efeito das relações de vizinhança. In: MARQUES, E.; TORRES, H. da G. (Eds.). São Paulo: segregação, pobreza e desigualdade. São Paulo: Editora do Senac, 2005.

VIGNOLI, J.R. Segregación residencial socioeconómica: ¿qué es?, ¿cómo se mide?, ¿qué está pasando?, ¿importa?. Serie Población y Desarrollo. Santiago do Chile: Cepal, 2001.

WILSON, J. Studying inner-city social dislocations: the challenge of public agenda research: 1990. American Sociological Review, v.56, n.1, p.1-14, 1991.

The truly disadvantaged. Chicago: The University of Chicago Press, 1987.

\section{Resumén}

Segregación socioespacial e inserción en el mercado de trabajo en la Región Metropolitana de Campinas

Partiendo de la premisa de que el "espacio es importante", el presente estudio procura aportar a los esfuerzos analíticos destinados a investigar el impacto de la segregación, que aquí se la entiende como la concentración en el espacio de estratos socioeconómicos semejantes, 
sobre la capacidad de respuestas de las personas o familias a los diversos problemas y riesgos observados en las grandes aglomeraciones urbanas. Más específicamente, este artículo pretende investigar, para el caso de una región metropolitana emergente en Brasil (Campinas, en el Estado de San Pablo), si hay evidencias del efecto de la segregación sobre distintas características de la inserción de los individuos en el mercado de trabajo. A partir de los datos del Censo Demográfico de 2000, se analiza de qué forma el desempleo, la formalidad del trabajo y la protección social de la población económicamente activa estarían influenciados tanto por las características sociodemográficas, incluyendo el estatus migratorio y la condición de movilidad intraurbana (pendularidad), como por su localización en el espacio regional. Como variable espacial relacionada con la segregación, se propone una medida basada en el Índice de Moran Local, que procura identificar áreas homogéneas en términos de la composición socioeconómica de sus habitantes. Los resultados obtenidos, aunque no concluyentes, sugieren la importancia de la localización sobre la forma de inserción de los individuos en el mercado de trabajo, lo cual corrobora algunas proposiciones teoréticas que se han tenido en cuenta en ese estudio.

Palabras-clave: Segregación habitacional. Mercado de trabajo. Movilidad espacial de la población.

\section{Abstract \\ Socio-spatial segregation and insertion in the labor market in the Metropolitan Region of Campinas, Brazil}

Based on the premise that "space matters," the present study is intended as a contribution to the analytic efforts focused on investigating the impact of segregation, understood here as how the concentration in space of similar socioeconomic strata affects the ability of individuals and families to respond to the numerous problems and risks involved in large urban areas. More specifically, the article consists of an investigation into whether, for the case of an emerging metropolitan region in Brazil (Campinas, in the State of São Paulo), there are indications of the effect of segregation on the various characteristics of the inclusion of individuals in the labor market. Data from the Federal Demographic Census of 2000 show how unemployment, formality of labor, and the social protection of the economically active population are influenced both by the sociodemographic characteristics, including migratory status and condition of intraurban mobility (pendularity), and by the population's physical location in the region. As a spatial variable related to segregation, a measure is proposed on Moran's Local rate, which seeks to identify homogeneous areas in terms of the socioeconomic composition of their inhabitants. Although the results obtained are not conclusive, they do suggest the importance of location on way individuals are absorbed by the labor market. This finding corroborates several of the theoretical propositions taken into account in this study.

Keywords: Residential segregation. Labor market. Spatial mobility of the population.

Recebido para publicação em 18/08/2009

Aceito para publicação em 29/01/2010 